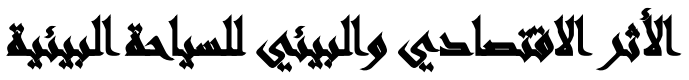

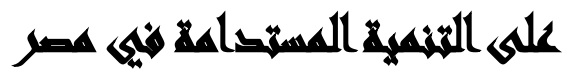

[iv]

$$
\begin{aligned}
& \text { سامية إبراهيم(')- صفوت عبد السلام (r)-- هدى سيد(r) } \\
& \text { محمود حامد (؛) }
\end{aligned}
$$

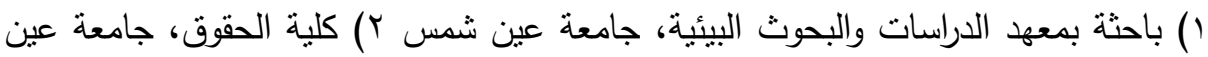

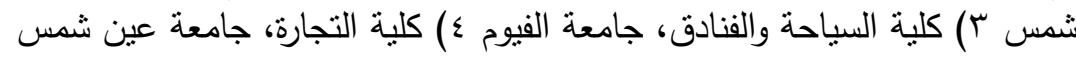

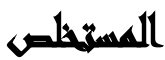

يستهدف هذا البحث دراسة الأثر الاقتصادي والبيئي للسياحة البيئية على التتمية المستدامة

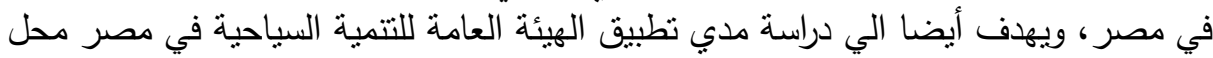

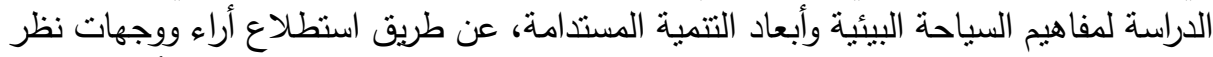

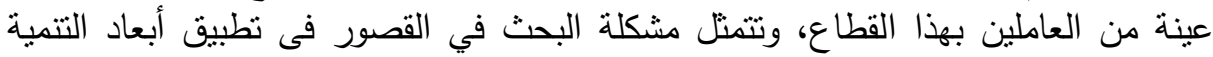

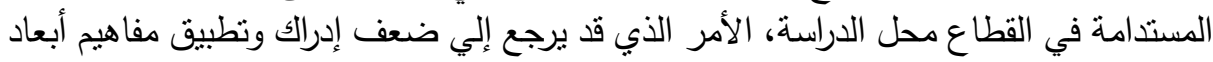

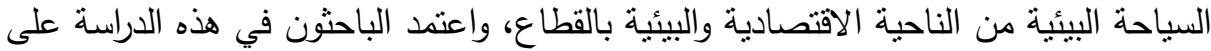

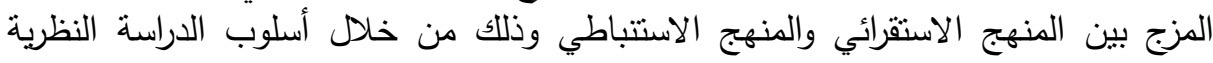

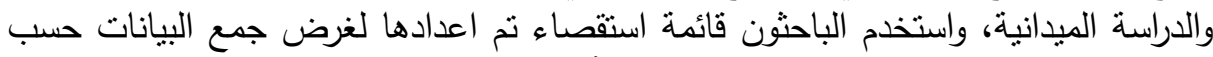

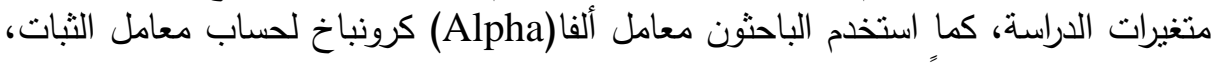

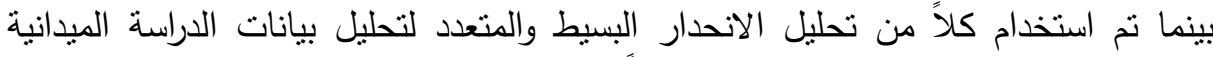

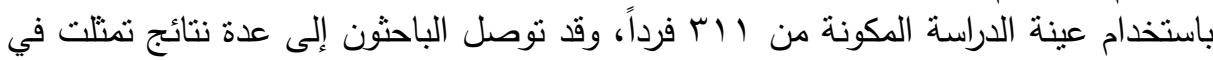

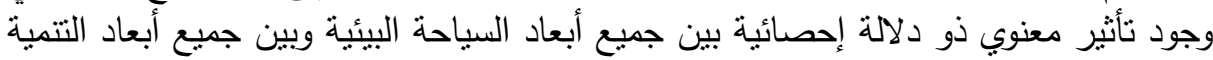

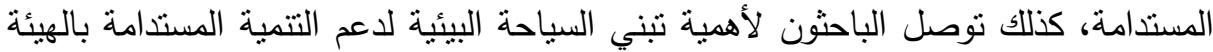

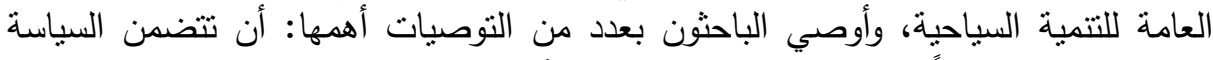

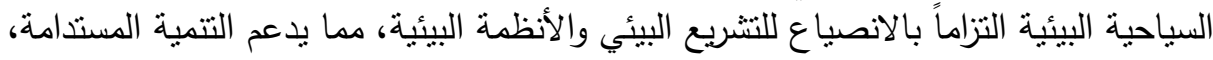

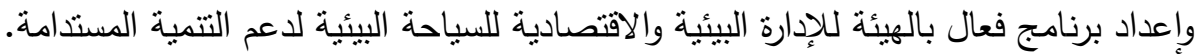

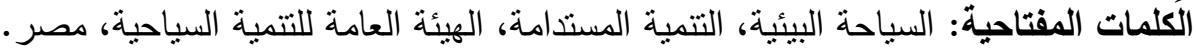




\section{Xan}

السياحة البيئية هي القطاع الأسرع نموًا في صناعة السياحة العالمية، وتوفر الحفاظ على

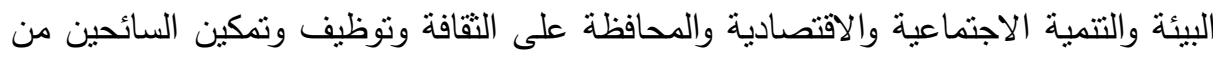

وجهات السياحة البيئية. (Sambou, O., Riniwati, H., \& Fanani, Z., 2019) فالسياحة هي ظاهرة عالمية ذات تأثير اقتصادي، اجتماعي وثقافي متزايد، لذا فإنه يجب

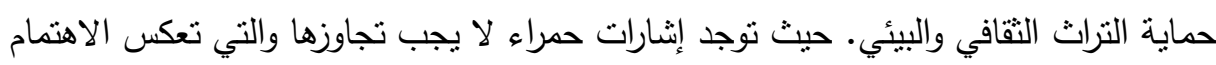

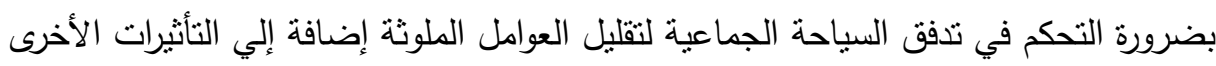

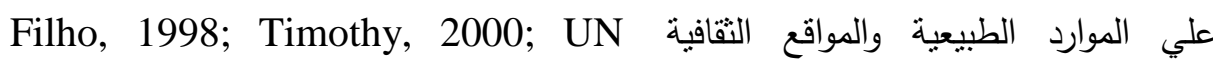
(ESCAP,2001)

حيث تعتبر البيئة هي القاعدة الأساسية في إدارة الموارد الثقافية والبيئية من أجل جذب أبن

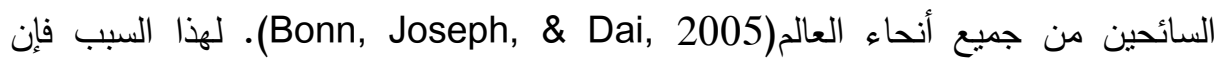
المحافظة علي الموارد البيئية ضروري ومؤثر جداً من أجل نجاح التنمية السياحية علي المدي البعيد. كما تعتبر الطاقة الحاملة القصوى هي طريقة مهمة في التخطيط الاقتصادي المستدام

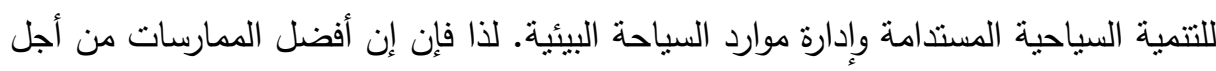
إدارة موارد البيئة هو تعظيم الاستخدام والذي يمكن أن يتم في المواقع السياحية دون إحداث

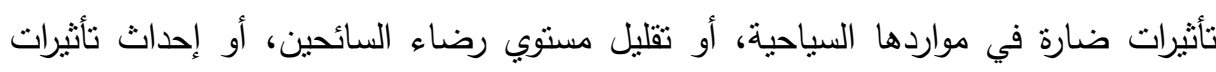

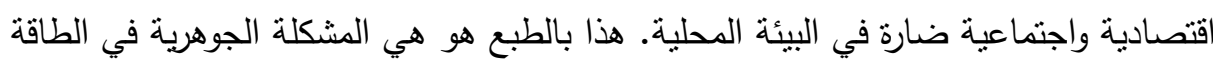

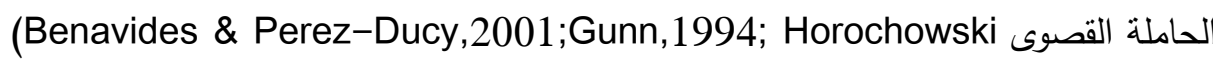
\& Moisey,2001; sharply,2001) الموارد البيئية وتقليل حجم التلوث. باختصار كما إنه من المهم أيضاً أن يتم التحكم في التتمية التهان

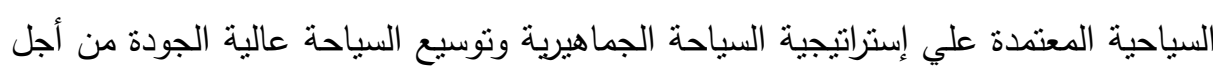
تحقيق متطلبات الاستدامة European Commission, 1995; Mowforth \& Munt .1998, pp:105-111). 
وفي ظل التتوع الثقافي الحالي، أصبحت الرموز الثقافية للتراث التقافي غير المادي بسبب

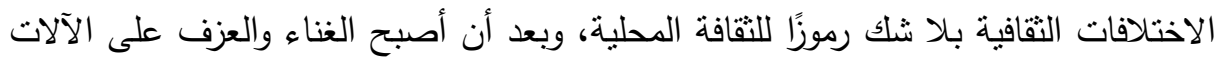
مثلاً نراثًا تقافيًا غير ملموس، جعلت الحكومات من العزف على الآلات الموسيقية في رمزًا تقافيًا مهمًا من أجل إظهار الخصائص الثقافية، ومع ذلك، حتى مع الدعوة القوية للحكومة لا نتزال

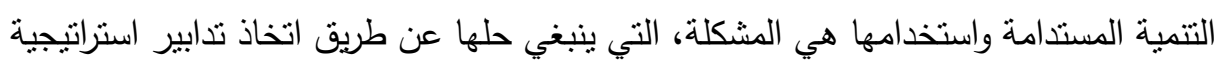

لمزيد من السياحة الثقافية والبيئية. (Chunai, X., \& Qin, L., 2018).

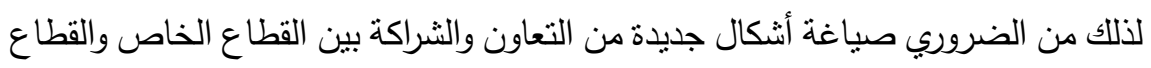

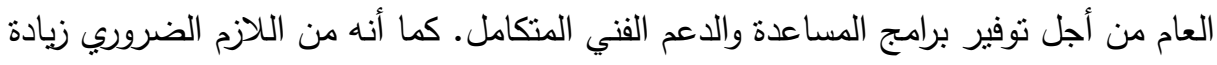
درجة الوعي بأهية التتمية المستدامة لدي السكان المحليين، وتصميم مؤشرات مناسبة في مجال الاستدامة السياحية، واختيار أماكن محددة من أجل التركيز علي تتمية السياحة البيئية، وإدارة

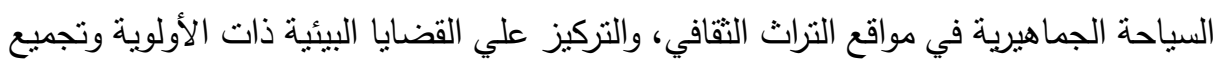
المعلومات الكاملة حول هذه القضايا، كذللك الأخذ في الاعتبار الأسباب الإضافية للتأثيرات علي لئي

البشر والبيئة (Moisey \& McCool, 2001; Phillips, 2000; Yunis, 2002). وحيث أن الهيئة العامة للتمية السياحية هى السلطة الاقتصادية العامة التي تدير وتستغل جميع الأراضي المخصصة لأغراض إقامة المناطق السياحية، ومقرها الرئيسي في القاهرة، ولها فروع في محافظات أخرى.(http://www.tda.gov.eg ) لذا من هذا المنطلق فإن هذه الدراسة تهدف لقياس الأثر الاقتصادي والبيئي للسباحة البيئية

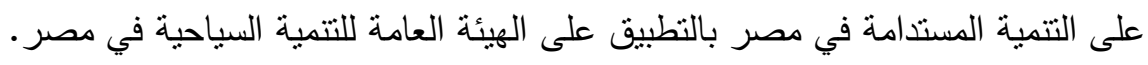

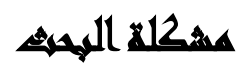

تتتامى أنشطة السياحة البيئية فى العالم بمعدلات تفوق القطاعات الأخرى من السياحة

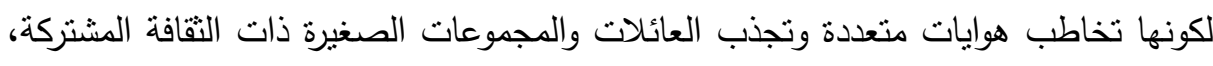
ويجد فيها الجميع التتوع الذى يلبى رغباته، وتضم السياحة البيئية فى مصر العديد من الأنشطة.

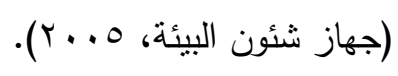


إلا أن ذلك يجب أن يكون لله مردود اقتصادي وبيئي ليعمل على تحقيق التتمية المستدامة. لذلك اعتمد الباحثون على القيام بدراسة استطلاعية ميدانية لتحديد مشكلة الدراسة باستخدام قائمة استقصاء مبئية لتجميع البيانات من عينة عشوائية مكونة من 30 مفردة من العاملين

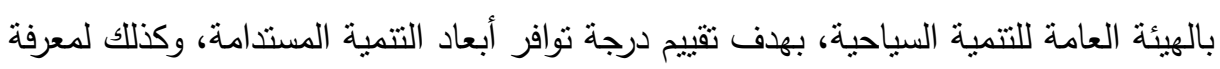
مدى إدراك الإدارة لتنبي السياحة البيئية من الناحية الاقتصادية والبيئية.

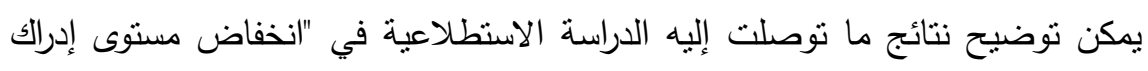

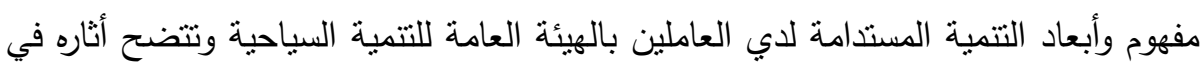

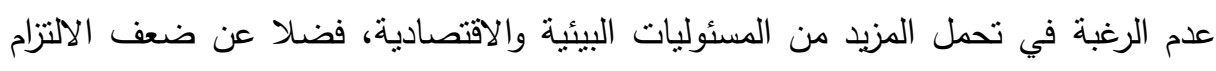
البيئي، وضعف التخطيط الاقتصادي المستدام، وزيادة معدل التلوث الناتج عن عدم إدراك أبعاد السياحة البيئية.

\section{أسهئل المهثم}

يحاول الباحثون من خلال هذه الدراسة الإجابة على التساؤل الرئيسي التالي: ما الأثر

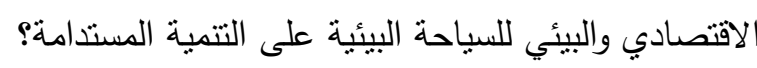

\section{وينبثق من هذا التساؤل الرئيسي التساؤلات الفرعية التالية:}

ا ـ ما مدي وجود تأثثر للسياحة البيئية من الناحية الاقتصادية والبيئية على التتمية المستدامة لتئية

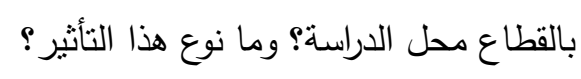

r. ما المستوى الاقتصادي والبيئي اللازم للسياحة البيئية في القطاع محل الدراسة لتحقيق التتمية

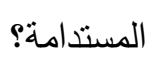

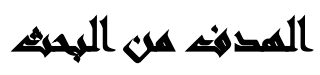

يهدف هذا البحث بشكل عام إلى دراسة واقع تبني القطاع محل الدراسة للسياحة البيئية وأثر ذلك على التتمية المستدامة، كما نذكر من أهدافه:

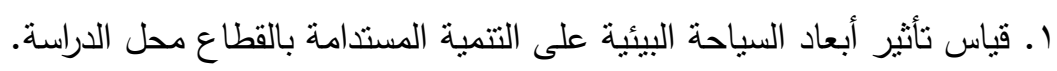
r. دراسة مدي إدراك إدارات هذا القطاع لأهمية في الوفاء بمسئوليته تجاه المجتمع والبيئة.

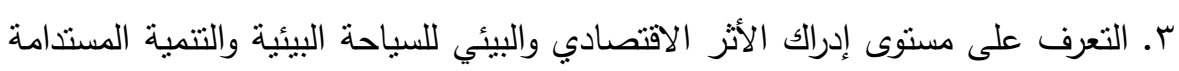




\section{هزوضر اللهمثر}

لتحقيق أهداف الدراسة والإجابة عن تساؤلاتها، فقد تم بناء الفروض التالية: الفرض الرئيسي الأول: لا يوجد تأثنراً معنوياً للسياسة السياحية البيئية كأحد أبعاد السياحة البيئية على أبعاد التتمية المستدامة (المنظور البيئي، المنظور الاقتصادي والتقني، المنظور الاجتماعي) في القطاع محل الدراسة. الفرض الرئيسي الثاني: لا يوجد تأثيراً معنوياً للتخطيط الاقتصادي المستدام كأحد أبعاد السياحة البيئية على أبعاد التتمية المستدامة. الفرض الرئيسي الثالث: لا يوجد تأثيراً معنوياً للسياسة الاقتصادية كأحد أبعاد السياحة البيئية على أبعاد التتمية المستدامة. الفرض الرئيسي الرابع: لا يوجد تأثيراً معنوياً للتشريعات السياحية البيئية كأحد أبعاد السياحة

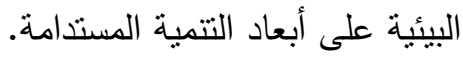
الفرض الرئيسي الخامس: لا يوجد تأثيراً معنوياً للحوافز المالية والضريبية الخضراء كأحد أبعاد السياحة البيئية على أبعاد التتمية المستدامة.

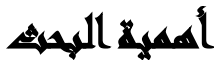

تتبع أهمية البحث من الدور الذي تلعبه عمليات السياحة البيئية في مواجهة ما يشهده العالم في تغيرات بيئية بسبب التطور التكنولوجي في المجال الصناعي، مما استدعي إبراز أثز تطبيق نظم الإدارة البيئة والجدوى الاقتصادية للسياحة البيئية على التتمية المستدامة كحافز

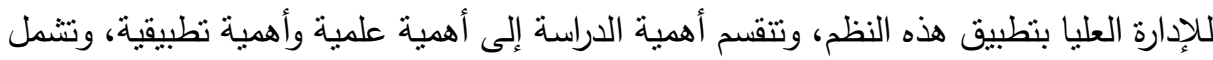
ما يلي:

الأهمية العلمية: تتمثل أهمية هذه الدراسة على المستوي العلمي فيما يلي:

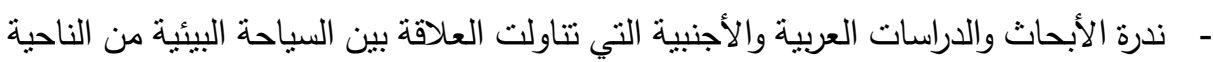

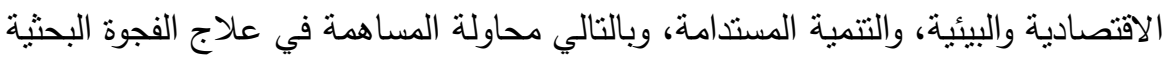

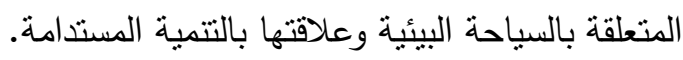
- التعرف على أثر تبني السياحة البيئية من الناحية الاقتصادية والبيئية على النتمية المستدامة. 
الأهمية العملية: تتمنل أهية هذه الدراسة على المستوي التطبيقي فيما يلي:

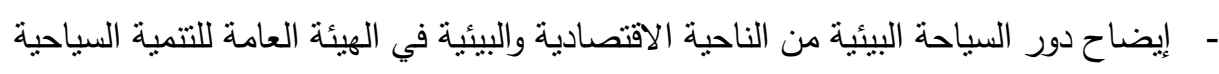
وأثرها على مستوي التتمية المستدامة. - أهمية القطاع محل الدراسة فهو يعد من القطاعات الحساسة والمهمة، لما لذلك القطاع من

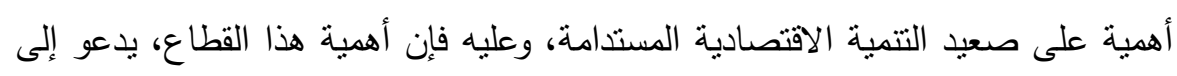
إجراء منل هذا النوع من الدراسات لضمان استمراريته وتطويره.

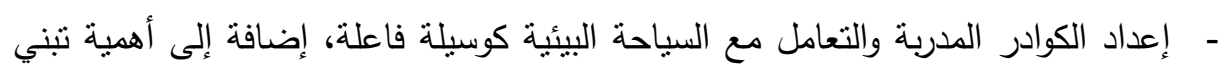

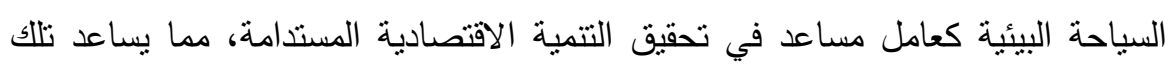
المؤسسات في تحقيق أهدافها الاستراتيجية.

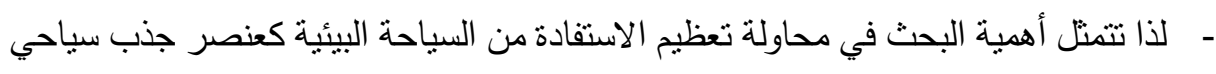
يمكن أن يساهم في تدعيم وتتشيط الحركة السياحية لمصر وتصبح وسيلة فعالة في مواجهة هذه التحديات، كذلك كيفية استغلال المنطقة سياحياً الاستغلال الأمتل من خلال تتشيط

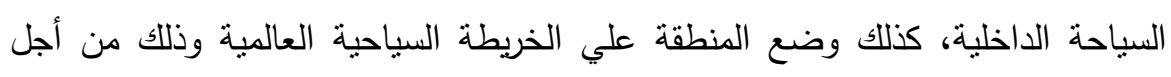

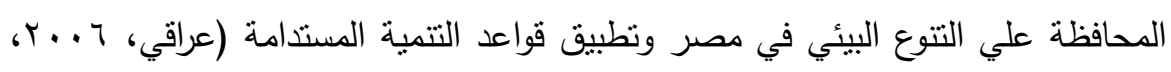

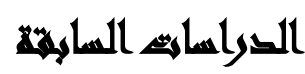

ا-دراسة (إبراهيم، Y I ـ Y)، بعنوان " إدارة موارد السياحة البيئية كوسيلة لتنمية السياحة المستدامة في مصر"، هدفت الي توفير إطار عمل تشريعي مناسب من أجل الحفاظ علي

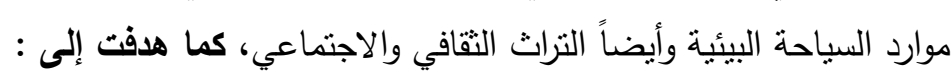

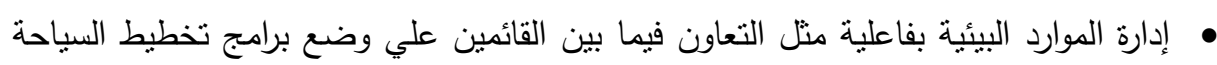

توفير إطار عمل تشريعي مناسب من أجل الحفاظ علي موارد السياحة البيئية وأيضاً التراث التقافي والاجتماعي. • التعاون الدولي في مجال إدارة موارد السياحة البيئية، الموارد النقافية وعملية إدارة التراث 
- - إثراك السكان المحليين في عملية تخطيط السياحة البيئية.

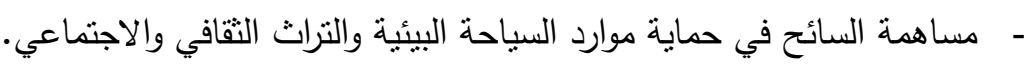
أهم النتائج تتوافر في مصر العديد من مقومات السياحة البيئية مما يجعلها قادرة علي تقديم

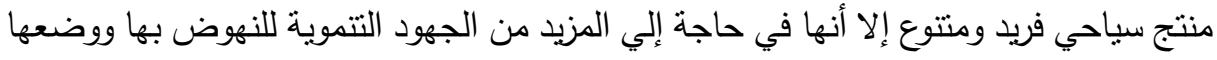
بشكل علمي مدروس علي الخريطة السياحية العالمية، وهناك العديد من معوقات تتمية السياحة

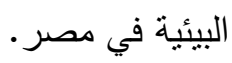

أوجه الاختلاف تختلف الدراسة السابقة عن الدراسة الحالية في أنها تعتمد على المنهج التحليلي الوصفي، وذللك لتتمية السياحة البيئية في مصر والتعرف علي المشكلات والمحددات التي تواجهها بنظام المسح الثامل. ودن. r-دراسة (Coronado Martínez, Y., et al., 2018): بعنوان " السياحة البيئية كطريق للتمية المستدامة في مدينة ماجيك تاون المعزولة- دراسة حالة لا ترامبا، Ecotourism as a path to sustainable development in an المكسيك"، isolated Magic Town: The case study of La Trampa, Mexico. تهدف هذه الدراسة إلى الكثف عن إمكانات السياحة البيئية في منطقة ذات مؤشر تهميش

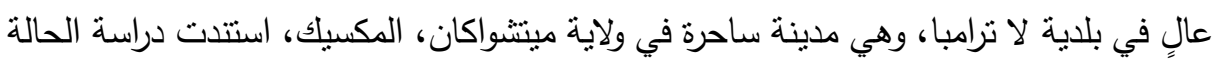
هذه إلى عدة منهجيات. أولاً، تم استخدام المتغيرات الاجتماعية والاقتصادية والبيئية والاستدامة لئه

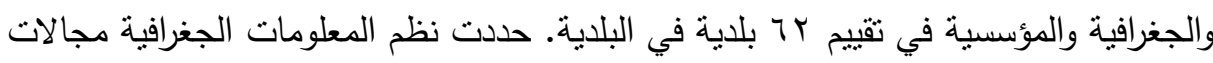

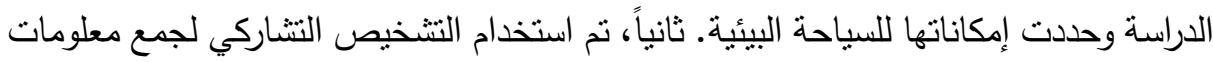

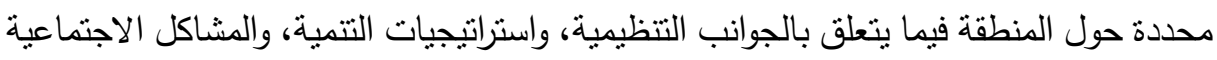
الاقتصادية الحالية، واستخدام الأراضي وتوافر الموارد والاهتمام بتطوير المشروعات المتعلقة بالسياحة البيئية. أخيرًا، قام الباحثون بتكييف نموذج FAS (العوامل والجاذبات وأنظمة الدعم)

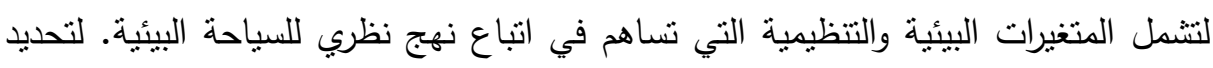
الجاذبين. 
وكانت أهم النتائج يخلص الباحثون إلى أن السياحة البيئية هي بديل محتمل للمواقع المهشة للغاية داخل بلديات ماجيك تاون، وسوف تكون قادرة على توسيع الفوائد الناتجة عن البرنامج.

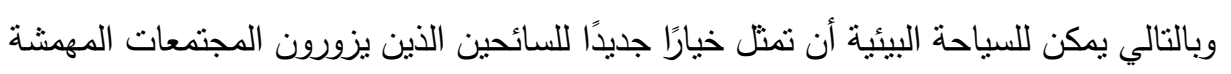
في المكسيك.

أوجه الاختلاف: تختلف الدراسة السابقة عن الدراسة الحالية في أنها تتعرض لقطاع دراسة مختلف وكذلك بعض الأبعاد ذات التأثثر في الاستدامة كالجاذبات وأنظمة الدعم.

ب-دراسة (Sambou, O., et al., 2019): بعنوان "الاستدامة الاجتماعية والاقتصادية والبيئية للسياحة الإيكولوجية- دراسة في غابة أويود في بالي، إندونيسيا"،

Socio-economic and Environmental Sustainability of Ecotourism: A Study in Ubud Monkey Forest-Bali, Indonesia.

هدفت هذه الدراسة إلي إيجاد الاستدامة الاجتماعية والاقتصادية والبيئية للسياحة البيئية

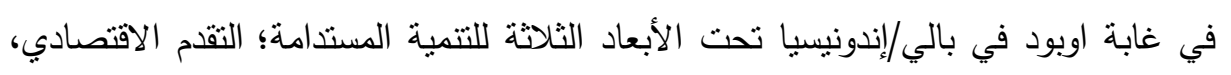

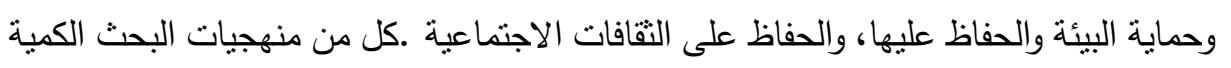

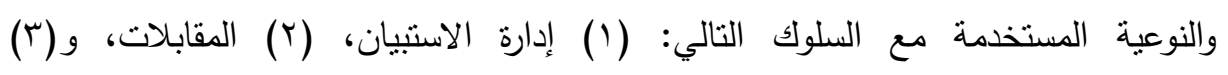

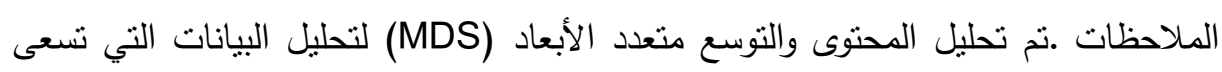

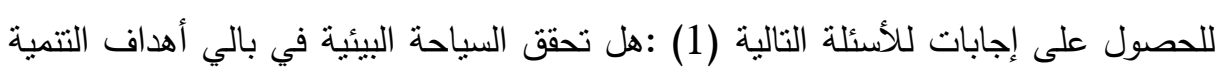

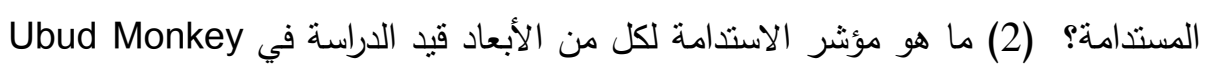
PForest

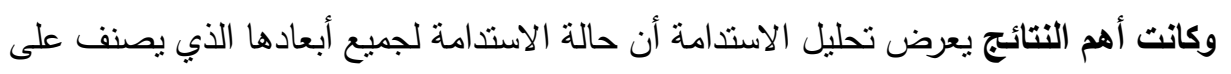

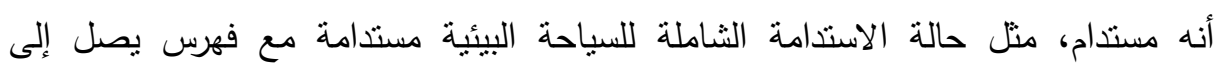


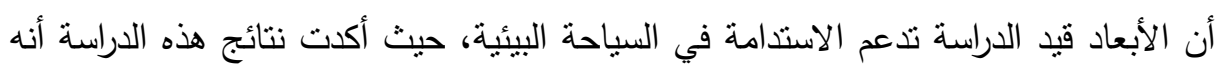

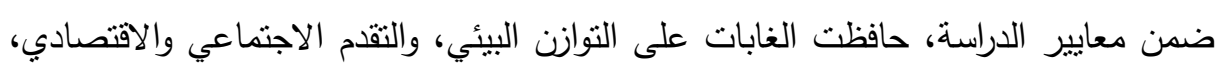
والحفاظ الثقافي .السياحة البيئية لديها إمكانات جذب عالية لكل من الشركات السياحية والمحلية 
مع التأثير بشكل أقل على الثقافة والبيئة والممارسات التقليدية للثعب البالي .على الرغم من ذللك، هناك مشكلة عامة تتمنل في تغيير استخدام الأراضي وإدارة النفايات في بالي.

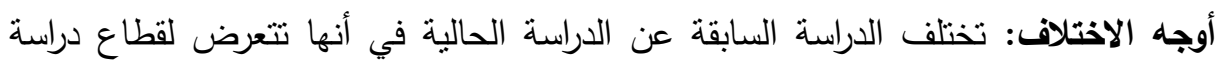
مختلف وكذلك بعض الأبعاد ذات التأثير في الاستدامة كالحفاظ النقافي. ع-دراسة (Liu, C., Lin, W., Wang, Y., \& Chen, S., 2019)، بعنوان " مؤشرات Sustainability الاستدامة لسياحة المهرجانات - منظور أصحاب المصلحة المتعددين ،"indicators for festival tourism: A multi-stakeholder perspective هدفت الدراسة الى المساعدة في تقييم سياحة المهرجانات المستدامة، حيث تقوم هذه الدراسة بتطوير مؤشرات استدامة لسياحة المهرجانات من خلال تضمين وجهات نظر من أربعة

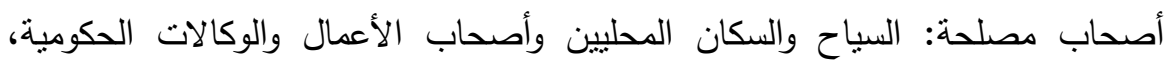

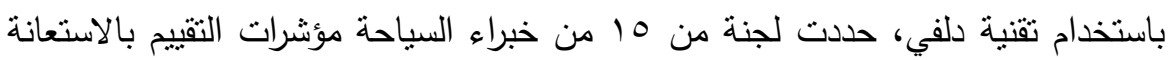
بالدراسات السابقة.

أهم النتائج: توصل الخبراء إلى توافق حول · r مؤشراً: السياح (أربعة مؤشرات)، السكان

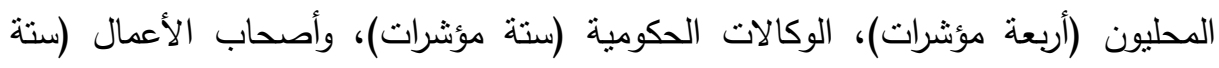

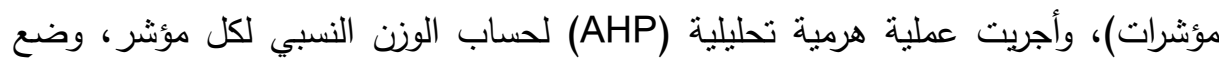

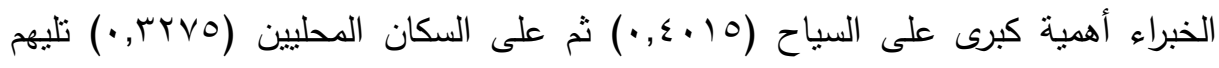

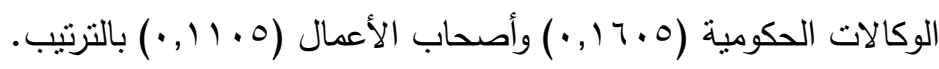
أوجه الاختلاف: تختلف الدراسة السابقة عن الدراسة الحالية في انها تعتمد على منهجية الاستقصاء، والدراسة الميدانية، كما أن الدراسة الحالية طبقت على العاملين بالهيئة العامة للتتمية السياحية في مصر. 
ما يميز هذه الدراسة عن غيرها من الدراسات السابقة: تتميز هذه الدراسة عن غيرها من

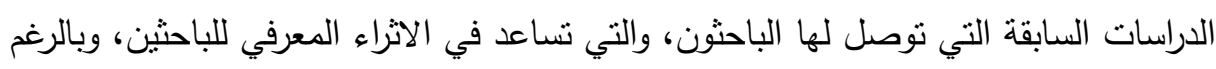

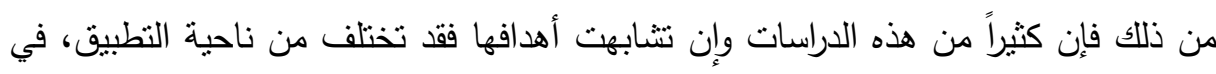
المكان والزمان، وحجم العينة، ومتغيرات أخري.

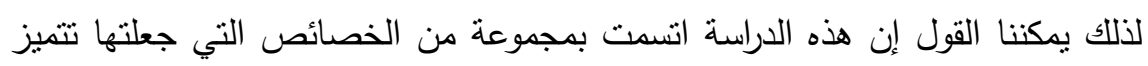

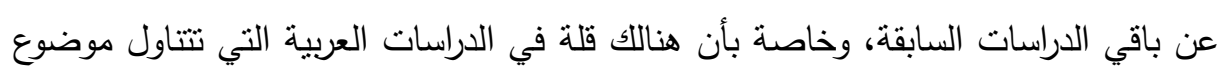

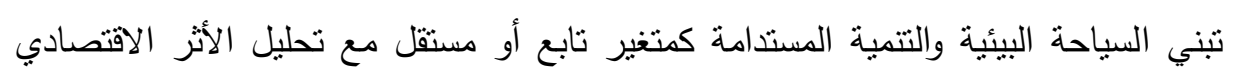

$$
\text { والبيئي، ومن هذه الميزات ما يلي: لئي }
$$

- تتاولت هذه الدراسة الأثر الاقتصادي والبيئي للسياحة البيئية على التتمية المستدامة في مصر ، وعلى حسب علم الباحثين بأنه لا توجد دراسة في الوطن العربي عامة ومصر خاصة لائي

$$
\text { تنتاولت ذلك. }
$$

- ميزت هذه الدراسة باختيارها بالمجتمع الذي طبقت عليه، حيث تمت الدراسة على الهيئة

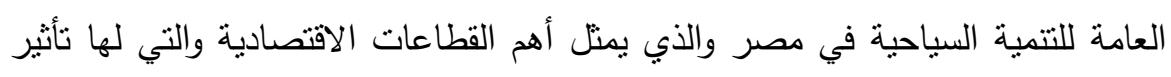

$$
\text { مباشر على البيئة. }
$$

- - تساهم هذه الدراسة في رفع المخزون المعرفي حول واقع تنبي السياحة البيئية، لذا يحاول

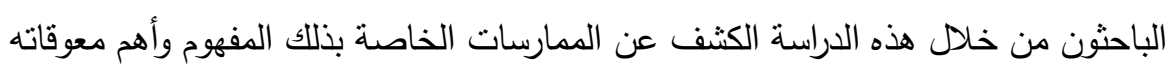
وسبل تطبيقه في قطاع التطبيق من أجل بناء إطار متكامل لتطبيق هذا الفكر بناءً على هلى

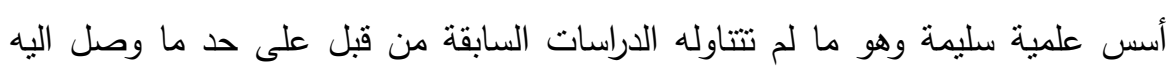
الباحثون من أدبيات. - - ستحاول هذه الدراسة الاستفادة من نقاط القوة في الدراسات السابقة ومحاولة تطويرها

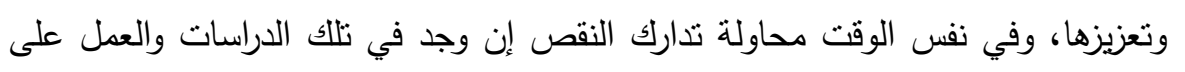

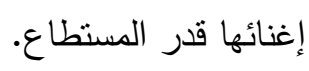




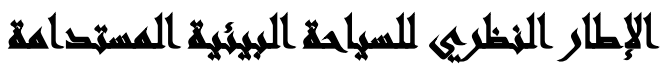

يستعرض الباحث الإطار النظري للبحث من خلال التالي:

السياحة البيئية: شهدت ثمانينيات القرن العشرين بدء ظهور مصطلح السياحة البيئية eco- tourism ، والذي يمنل أحد الاتجاهات الحديثة للسياحة العالمية، وذلك لاعتبارها أحد الأنماط السياحية الصديقة للبيئة والتي ظهرت نتيجة للتراث الطبيعي والحضاري والمجتمعات

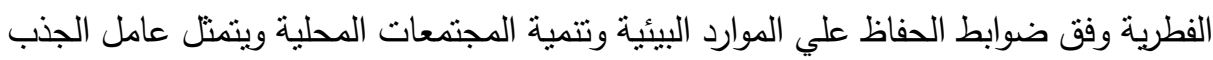
الرئيسي لهذا النمط في رغبة البعض للعودة إلي الطبيعة بعيداً عن الضغوط اليومية للحياة، وفي

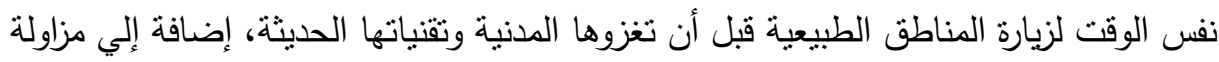

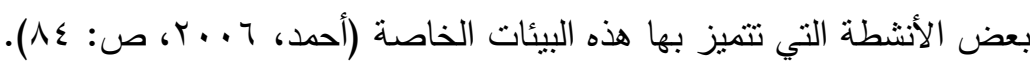

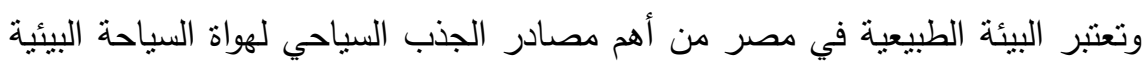

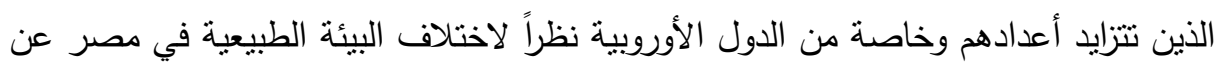

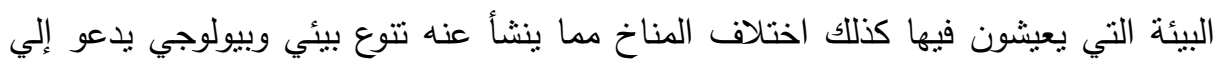

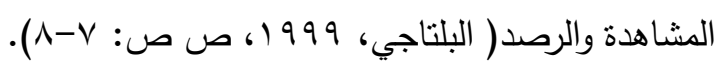
ولقد وضعت وزارة السياحة المصرية إستراتيجية تتمية السياحة البيئية والتي تضمنت مجموعة من الأسس المهنمة بالجوانب البيئية. حيث توفر هذه الإستراتيجية اعتبارات مهمة

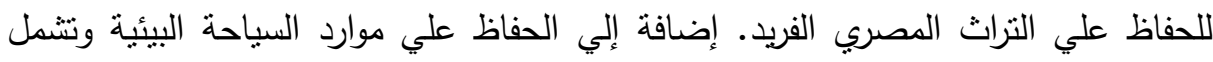
أولويات تتمية السياحة البيئية الساحل المصري لخليج العقبة، الساحل الثمالي الغربي، المنطقة الممتدة بين الغردقة حتي سفاجا في البحر الأحمر، سياحة اليخوت والبواخر النيلية بين القاهرة وأسوان (wahab, 2001).

ويلعب التخطبط السياحي دوراً بالغ الأهمية في تطوير النشاط السياحي، وذلك لكونه منهجاً

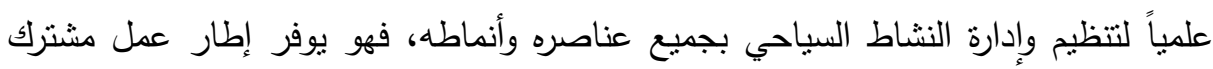

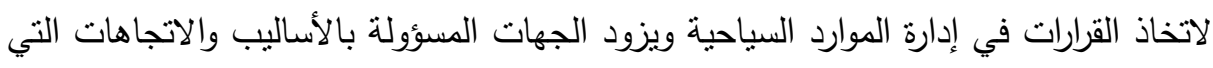
يجب أن تسلكها، مما يسهل عملها ويوفر كثيراً من الجهز الضائع، ويحقق التتمية المستدامة. 
التنمية المستدامة: يمكن تتاول التتمية المستدامة من خلال الآتي:

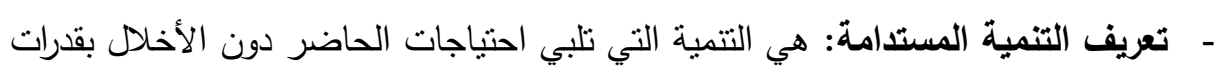
الأجيال القادمة على تلبية احتياجاتها أو هي تعبير عن التتمية التي تتصف بليفي بالاستقرار وتمتلك عوامل الاستمرار والتواصل وتتسم بالثمول والمدى الأطول والديمومة.

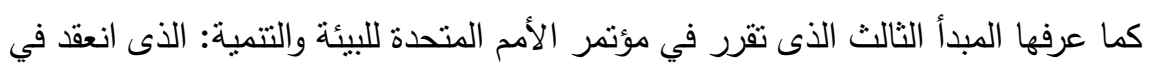

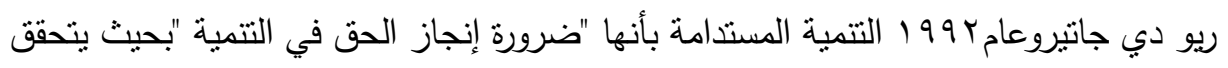
على النحو منساو الحاجات التتموية والبيئية لأجيال المستقبل. وعرفها أيضا مؤتمر منظمة الزراعة والاغذية العالمية (FAO) بأنها " إدارة قاعدة الموارد وصونها وتوجيه عملية التغير البيولوجي والمؤسسي على نحو يضمن إثباع الحاجات الإنسانية للأجيال الحاضرة والمقبلة بصفة مستمرة في كل القطاعات الاقتصادية، ولا تؤدي إلى تدهور البيئة وتتسم بالفنية والقبول.

وعرفتها الباحثة: أن التتمية المستدامة تعنى الاستخدام الرشيد والأمثل للموارد الطبيعية المتاحة لتحقيق التتمية الاقتصادية مع المحافظة على حق الأجيال المستقبلية لتلك الموارد والمحافظة على البيئة وتتميتها. طبيعة التنمية المستدامة: تعنى التتمبة النى تفى باحتباجات الوقت الحالي دون المساس بقدرة

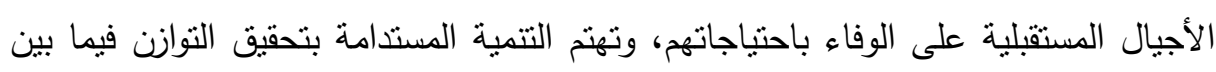

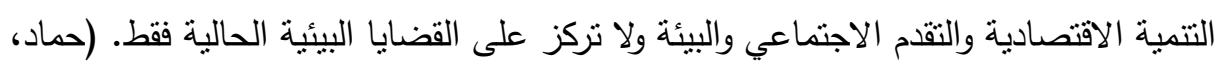

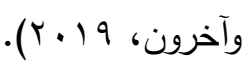
وعلى نطاق أوسع تتنتمل سياسات التتمية المستدامة ثلاثة مجالات للسياسة العامة وهى التى

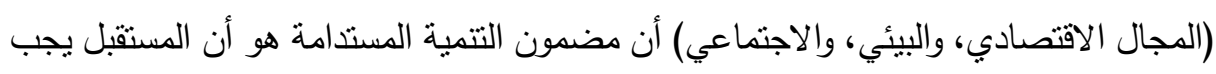

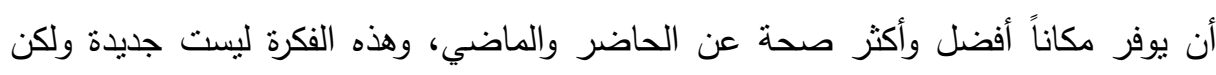
الطريق اليها هو المطلوب تهيئنه. 


\section{إجبراءيت القواسمة}

اعتمد الباحثتن في هذه الدراسة على المزج بين المنهج الاستقرائي والمنهج الاستتباطي وذلك من خلال أسلوب الدراسة النظرية والدراسة الميدانية بالاستقصاء وذلك كما يلي: الاراسة النظرية (المنهج الوصفي): في هذا الإطار اعتمدت الدراسة على المنهج الوصفي بهدف استقراء جوانب المشكلة محل الدراسة، واستعراض وتحليل نتائج الدراسات السابقة معتمدةً

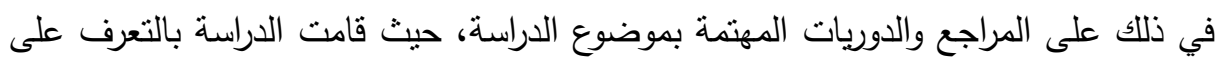

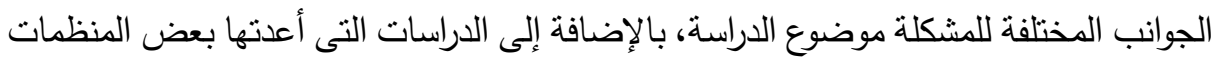
التى تراعى البعد البيئي بالدولة، وذللك للتعرف على طبيعة المشكلة والظروف المحيطة بها والمؤثرة عليها، وقد اعتمد الباحثون على بعض المراجع العربية والأجنبية المتاحة في هذا المجال

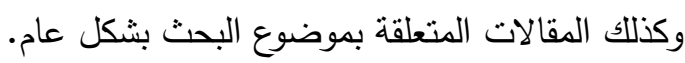
الدراسة الميدانية (المنهج التحليلي): اعتمد الباحثون في إجراء الدراسة الميدانية على

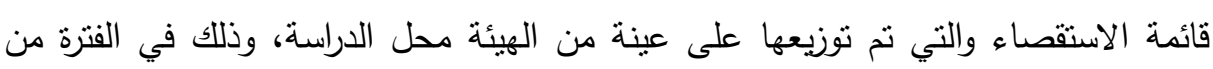

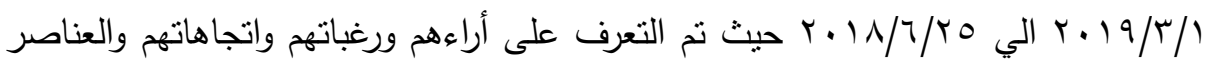
غير المرضية التى تواجهم وانطباعاتهم واقتراحاتهم، وقد تم استخدام الأساليب الإحصائية في تحليل البيانات والمعطيات التي تم جمعها. وقد توصلت الدراسة إلى وجود فجوة بحثية لم تغطيها العديد من الدراسات السابقة، ومن ثم اهتمت الدراسة بإجراء دراسة استكثافية في المجال التطبيقي، ثم تم استعراض نتائج الدراسة

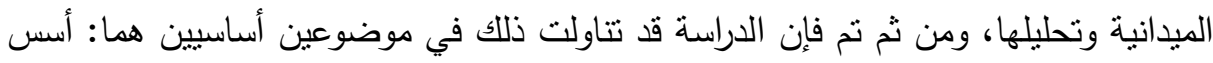

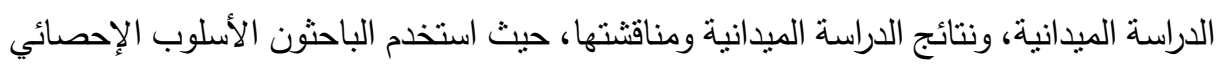
الأنسب للتحليل، وهو معامل ألفا(Alpha) كرونباخ لحساب معامل الثبات، بينما استخدم كلاً من معامل الارتباط لسبيرمان، وأسلوب تحليل الانحدار البسيط والمتعدد لتحليل بيانات الدراسة الميدانية، ولما كانت البيانات قد جاءت منظمة في شكل جداول تكرارات من خمسة أعمدة

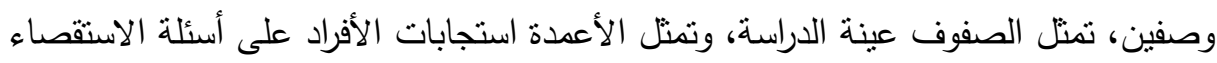

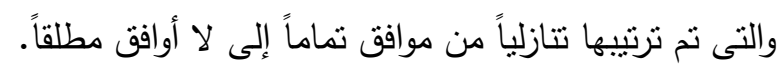

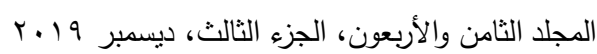




\section{أسلوب وأدوات الدراسة:}

\section{• مجتمع الاراسة والعينة: يمكن توضيح كلاً من مجتمع وعينة الاراسة كما يلي:}

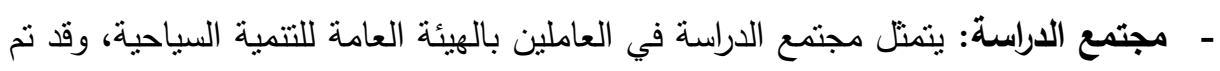
اختيار الفئات الثناثثة (إدارة عليا- إدارة وسطى - إدارة تتفيذية)، وإجمالي عدد الفئات الثناثئة •

$$
\text { وإدراك متغيرات الدراسة. }
$$

- عينة الاراسة: استعان الباحثون بطريقة العينة العثوائية الطبقية في اختيار عينة الدراسة، وقد استخدم الباحثون طريقة النسب والتتاسب، وتم اختيار عينة من مجتمع الدراسة باستخدام

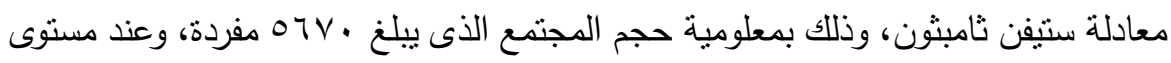
ثقة 95\% وحدود خطأ 土 5\%، وبعد ادخال البيانات للبرنامج نم حساب حجم العينة وبلغ 360 مفردة تقريباً، وكانت عدد الاستمارات الصحيحة التى تم استردادها هي

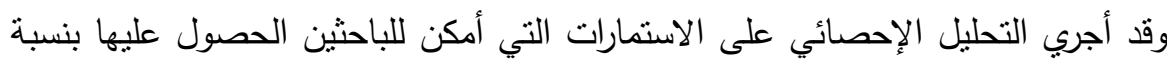
استرداد بلغت 86,39\%.

- قياس متغيرات الدراسة: في ضوء الدراسات السابقة التي اطلع عليها الباحثون، فقد اعتمد

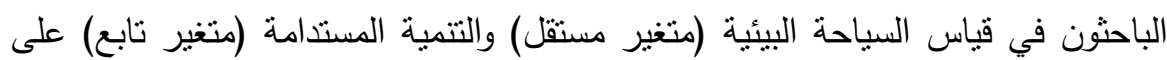
الأبعاد التالية:

× المتغير المستقل: (السياحة البيئية): تمثتك الأبعاد الخمسة التالية: (السياسة السياحية البيئية - التخطيط الاقتصادي المستدام -السياسة الاقتصادية -النتريعات السياحية البيئية الحوافز المالية والضريبية الخضراء).

× المتفير التابع: (التنمية المستدامة): من خلال الأبعاد الثلاثة التالية: (المنظور البيئي المنظور الاقتصادي والتقني -المنظور الاجتماعي). -

قام الباحثون بتصميم قائمة استقصاء لتجميع البيانات من مفردات البحث، حيث مر إعدادها وتصميمها بالخطوات التالية: 
الخطوة الأولى: إعداد قائمة الاستقصاء في صورتها الأولية: اعتمد الباحثون تصميم قائمة

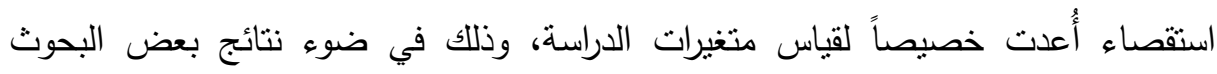

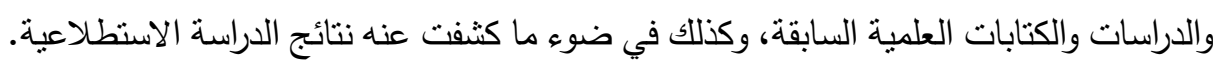

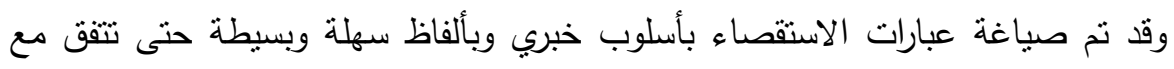

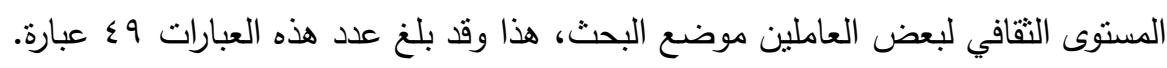

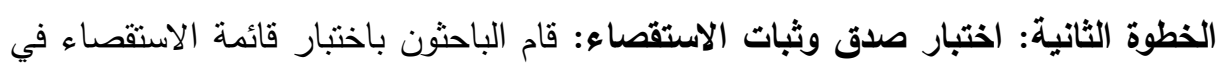

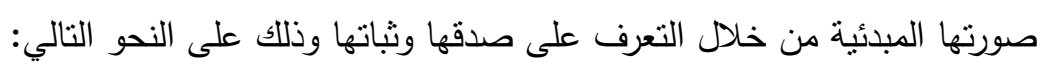

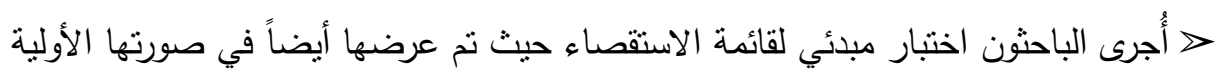

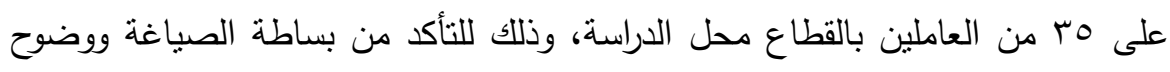
اللغة، وللنأكد أيضاً من صلاحية الاستقصاء من الناحية العيدانية.

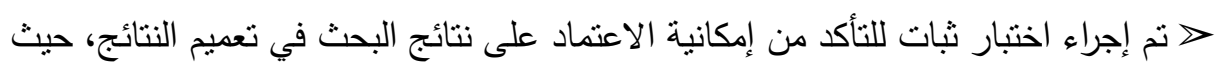

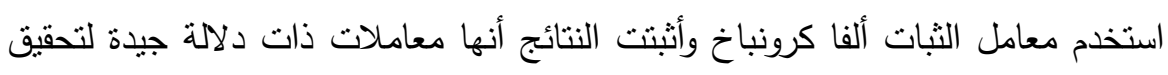

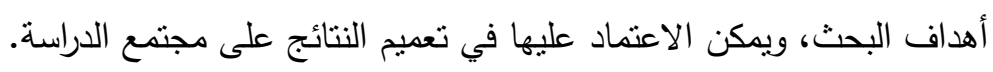

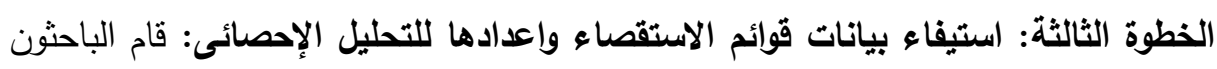

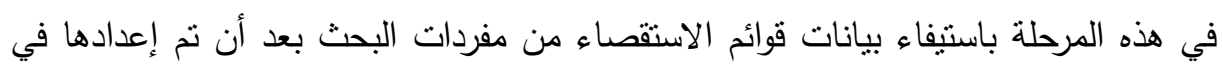

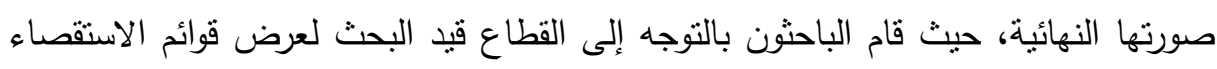

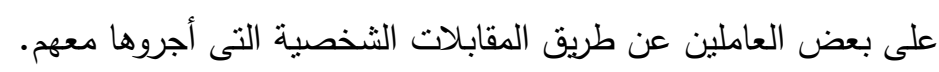

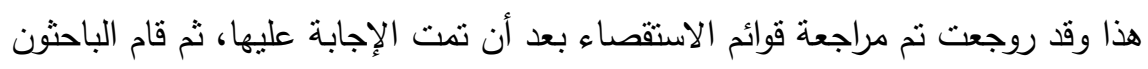

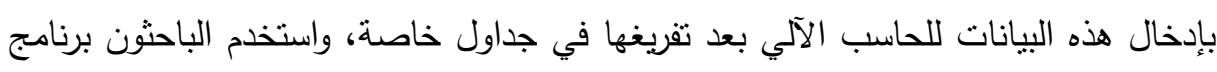
الحزم الإحصائية (SPS V25) في إجراء النحليل الإحصائي لبيانات الدراسة الميدانية. 


\section{أساليهب التحليل الإحسائيه}

اعتمد الباحثون على الأساليب التالية: ا ـ معامل الثبات (Alpha) كرونباخ: ويستخدم لحساب معامل الثبات، وذلك لبحث مدى البى إمكانية الاعتماد على نتائج الدراسة الميدانية في تعميم النتائج.

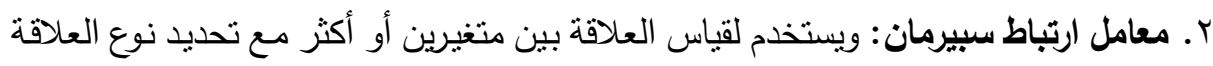
وقوتها. ז. أسلوب الانحدار البسيط: ويستخدم لحساب معاملات الانحدار للمتغير المستقل على المتغير التابع.

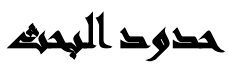

الحدود الزمنية: تتمنل الحدود الزمنية للاراسة في الفترة من أول مارس عام 9 اــ الي منتصف يونية عام 9 ـ ب الفترة الزمنية التى نم فيها الدراسة الميدانية. الحدود المكانية: كما تتمنل الحدود المكانية للبحث في الهيئة العامة للتمية السياحية ويرجع اختيار الباحثون لهذا القطاع الى أنه يعد من أهم الهيئات العاملة في القطاع التتموي

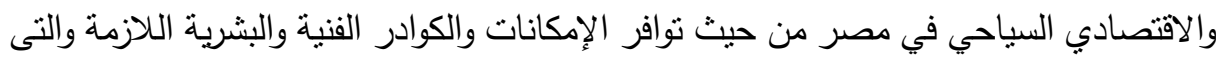
يمكن من خلالها انتاج وتصدير السياحة الخضراء للخارج ووضع نموذج يحتذى به في كافة القطاعات الأخرى في مصر -، والتى تتبع وزارة السياحة وتختص بوضع خطط تتمية المناطق السياحية والإشراف على تتفيذها، وتتفيذ مشروعات البنية الأساسية في المناطق السياحية، وإدارة واستغلال أراضي الدولة التي تخصص للأغراض السياحية.

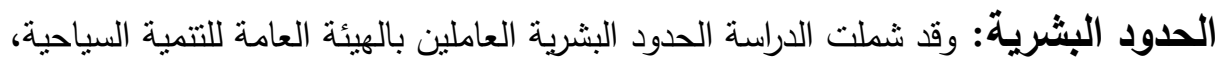
وقد تم شمل اختيار جميع العاملين من الفئات الإدارية المختلفة، حيث أن لديهم القدرة على فهر لهي وتحليل محاور الدراسة المختلفة. الحدود العلمية: اقتصرت الدراسة على دراسة أثز تبني السياحة البيئية بأبعادها الخمسة على التتمية المستدامة بأبعاده الثلاثة المذكورة، بالتطبيق على الهيئة العامة للتمية السياحية. 
صدق وثبات أداة ومقاييس الدراسة: قام الباحثون بإجراء اختبارات الصدق والثبات لقائمة الاستقصاء بغرض بحث مدى إمكانية الاعتماد على نتائج الدراسة الميدانية في تعميم النتائج

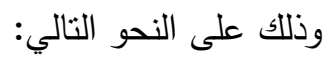

كما نم إجراء اختبار الثبات (Alpha) لمحتويات قائمة الاستقصاء، للتأكد من إمكانية الاعتماد على نتائج الدراسة الميدانية في تعميم النتائج، حيث تم الاعتماد على معامل الثبات

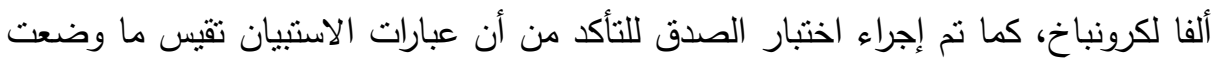

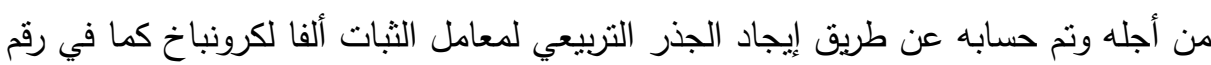

جدول رقم (1): معاملى الثبات لألفا كرونباخ والصدق الذاتى لاستمارة الاستقصاء

\begin{tabular}{|c|c|c|c|c|}
\hline معامل الصدقى & $\begin{array}{c}\text { (الثبات } \\
\text { (Alpha) }\end{array}$ & العبار & البيـان & المحاور \\
\hline$\cdot, 9 \cdot 1$ & $\cdot, \Lambda Y V$ & $\overline{r T}$ & السياحة البيئية & 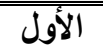 \\
\hline$\cdot, 919$ & $\cdot, \wedge \varepsilon \varepsilon$ & 7 & السياسة السياحية البيائية & 1 \\
\hline$\cdot, \wedge \uparrow \wedge$ & $\cdot$, VOT & 0 & التخطيط الاقتصادي المستدام & $\bar{r}$ \\
\hline$\cdot, 9 \leq \varepsilon$ & $\cdot, \wedge 9 Y$ & 7 & السياسة الاقتصادية & $r$ \\
\hline 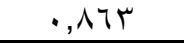 & $\cdot, V \leqslant 0$ & $r$ & النتريعات السياحية البيئية & $\varepsilon$ \\
\hline$\cdot, 9 \leq$ & $\cdot, \wedge \wedge \varepsilon$ & $r$ & الحوافز المالية والضريبية الخضراء & 0 \\
\hline., $9 \vee r$ & $\cdot, 9 \leqslant 7$ & ri & التنمية المستدامة & الثانى الثا \\
\hline$\cdot, 9 r \leqslant$ & $\cdot, \Lambda \vee T$ & 7 & المنظور البيئى & 1 \\
\hline$\cdot, 941$ & $\cdot$, АTV & 9 & المنظور الاقتصادي والتقنى & $r$ \\
\hline$\cdot, 9 T Y$ & $\cdot$, , 01 & 1 & المنظور الاجتماعى & $r$ \\
\hline
\end{tabular}

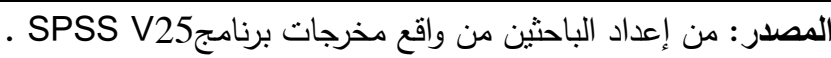
وباستعراض الجدول رقم (1) يتضح أن قيم معامل الثبات مقبولة لجمئن لجميع المحاور ، حيث

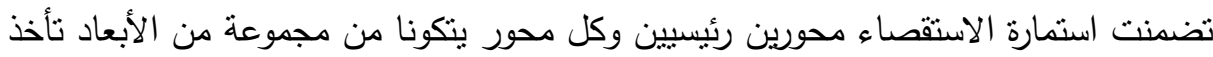

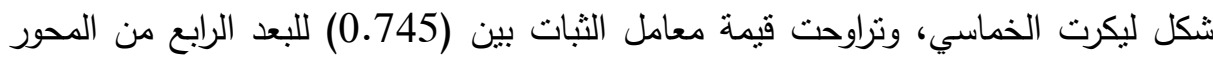
الأول " التشريعات السياحية البيئية " و(0.947) للمحور الثاني " التتمية المستدامة "'". 
وباستعراض جدول رقم (2) تراوحت قيمة معامل الصدق بين (0.863) للبعد الرابع من

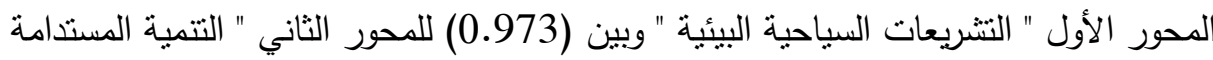
"'"'، حيث أن قيمة معامل الصدق الذاتي هي الجذر التربيعي لقيم معامل الثبات.

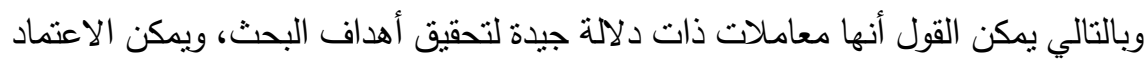

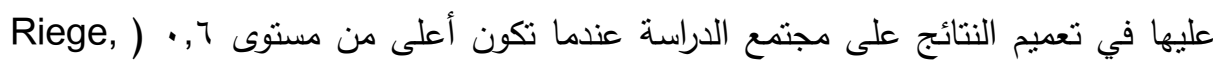

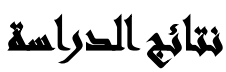

أ. اختبار فروض الدراسة: لاختبار فروض الدراسة نم اختبار وجود علاقة ارتباط معنوية

بين أبعاد السياحة البيئية وأبعاد التتمية المستدامة من وجهة نظر عينة الدراسة.

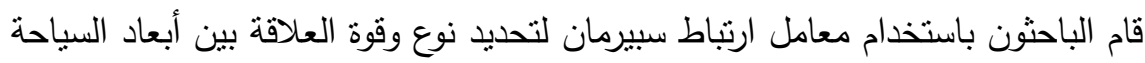

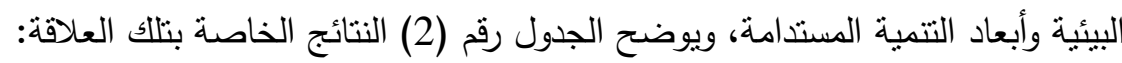
جدول رقم (Y): معاملات ارتباط سبيرمان بين أبعاد السياحة البيئية وأبعاد التتمية المستدامة

\begin{tabular}{|c|c|c|c|}
\hline الاجنماعى & الاقتصادي والتقتي & المنظور & متغيرات الدراسة \\
\hline **ฯะ. & $* * \vee Y \Lambda$ & "**qrV. & السياسة السياحية البيئية \\
\hline *yor. & *ฯフル. & **97r. & التخطيط الاقتصادي المستدام \\
\hline$* \eta \vee \cdot$. & 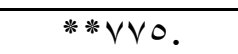 & **qu & السياستة الاقتصادية \\
\hline *ฯฯ1. & *ๆ ๆ I. & **qrl. & التشريعات السياحية البيئية \\
\hline *09r. & *ฯๆ . & **qץ^. & الحوافز المالية والضريبية الخضراء \\
\hline
\end{tabular}

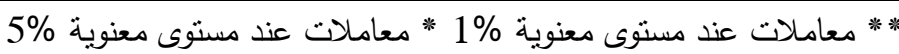

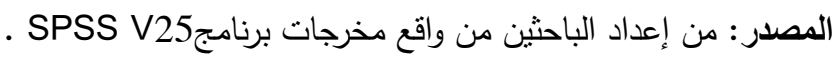
يتضح من الجدول رقم (2) وجود ارتباط طردى قوى بين (التخطيط الاقتصادي المستدام)

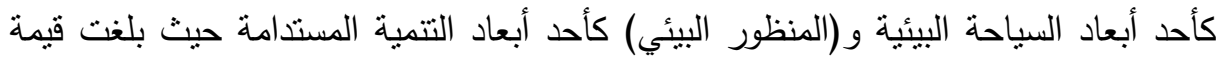
معامل الارتباط (0.962) ومعنوي عند مستوى معنوية 1\%، وتوجية واديد علاقة طرديه قوية بين (السياسة السياحية البيئية) كأحد أبعاد السياحة البيئية و (المنظور البيئي) كأحد أبعاد التنمية المستدامة حيث بلغت قيمة معامل الارتباط (0.937) ومعنوي عند مستوى معنوية 1\% 1 ، ويتضح من الجدول وجود علاقة طردية قوية بين (الحوافز المالية والضريبية الخضراء) كأحد أبعاد 
السياحة البيئية و(المنظور البيئي) كأحد أبعاد التتمية المستدامة حيث بلغت قيمة معامل الارتباط.(928 ) ومعنوي عند مستوى معنوية 1\%، وتوجد علاقة طردية قوية بين (التشريعات السياحية البيئية) كأحد أبعاد السياحة البيئية و (المنظور البيئي) كأحد أبعاد التتمية المستدامة حيث بلغت قيمة معامل الارتباط (0.921) ومعنوي عند مستوى معنوية 1\%، وكانت أقل قيمة وادئه لمعامل الارتباط بين (الحوافز المالية والضريبية الخضراء) كأحد أبعاد السياحة البيئية و (المنظور الاجتماعي ) كأحد أبعاد التتمية المستدامة حيث بلغت قيمة معامل الارتباط (0.593) مما بدل

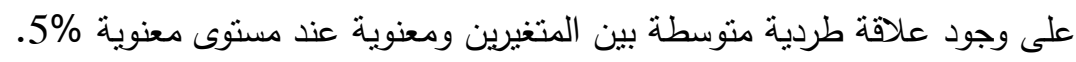

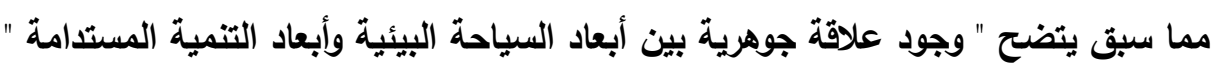

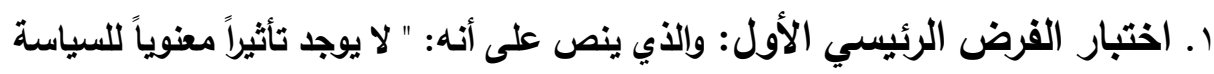

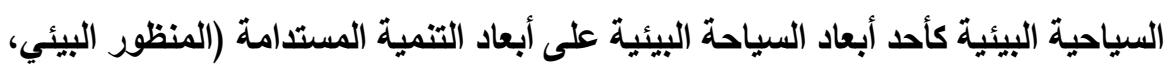

\section{المنظور الاقتصادي والتقني، المنظور الاجتماعي) في القطاع محل الدارةة."}

لاختبار هذا الفرض نم استخدام الانحدار البسيط يعرض جدول رقم (3) نقديرات نماذج الاجئ الانحدار البسيط لانحدار المتغيرات التابعة (منوسط آراء العينة حول أبعاد التتمية المستدامة) على السياسة السباحية البيئية. جدول رقم (ץ): تقديرات نماذج الانحدار البسيط للسياسة السياحية البيئية

\begin{tabular}{|c|c|c|c|c|c|c|}
\hline \multicolumn{4}{|c|}{ التقديرات } & \multirow{2}{*}{$\begin{array}{c}\mathbf{F} \\
\text { (sig.) }\end{array}$} & \multirow{2}{*}{ 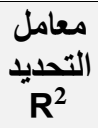 } & \multirow{2}{*}{ التتابغيرات التابعة } \\
\hline. Sig & $\mathrm{t}$ & Q & & & & \\
\hline$\cdot, \cdots$ & $1, \leqslant 0 V$ &., 094 & الثابت & \multirow[b]{2}{*}{ VY,TOE } & \multirow[b]{2}{*}{$\cdot, \wedge \wedge$. } & \multirow[b]{2}{*}{ المنظور البيئي } \\
\hline$\cdot, \cdots$ & $1,0.7$ & $\cdot, \wedge \wedge \wedge$ & السياحية البيئية & & & \\
\hline$\cdot, \cdots$ & $1,11 \varepsilon$ & $\cdot, 997$ & الثابت & \multirow[b]{2}{*}{$\begin{array}{l}\mid r, r \cdot 1 \\
\cdot, \cdot r\end{array}$} & \multirow[b]{2}{*}{$\cdot, V \leq 0$} & \multirow{2}{*}{ الاقتصادي } \\
\hline$\cdot, \cdots$ & r,r & $\cdot, \vee \vee 1$ & السياحية البيئية & & & \\
\hline$\cdot, \cdots$ & 1,911 & 1,71 & الثابت & \multirow{2}{*}{$\begin{array}{l}7, \vee \backslash 17 \\
\cdot, \cdots\end{array}$} & \multirow[b]{2}{*}{$\cdot, \wedge 19$} & \multirow{2}{*}{ الاجنماعي } \\
\hline$\cdot, \cdots$ & $r, 091$ & $\cdot, 0 \wedge \varepsilon$ & السياحية البيئية & & & \\
\hline
\end{tabular}


يتضح من الجدول رقم (3) معنوية نموذج انحدار المنظور البيئي على السياسة السياحية

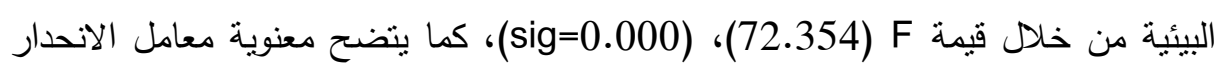
والحد الثابت عند مستوى معنوية 5\%. وبلغت قيمة معامل التحديد (0.880) مما يدل على ألى أن المتغير المستقل (السياسة السياحية البيئية) يفسر و التابع (متوسط آراء العينة حول المنظور البيئي).

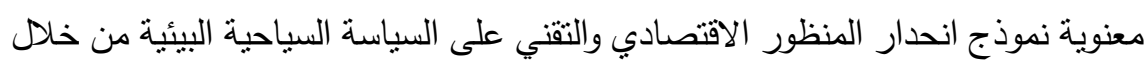

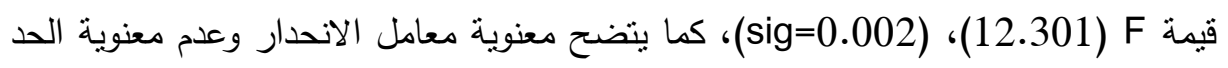
الثابت عند مستوى معنوية 5\%. وبلغت قيمة معامل التحديد (0.745) مما يدل على أن المتغير

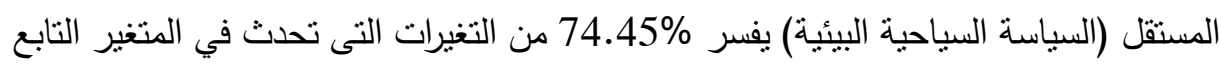

$$
\text { (المنظور الاقتصادي والتقني). }
$$

معنوية نموذج انحدار المنظور الاجتماعي على السياسة السياحية البيئية من خلال قيمة

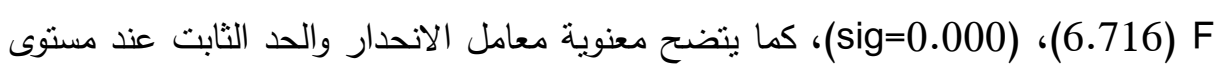

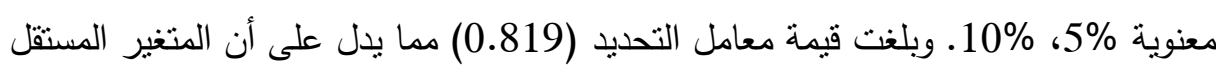
(السياسة السياحية البيئية) يفسر 81.9\% من التغيرات التى تحدث في المتغير التابع (المنظور

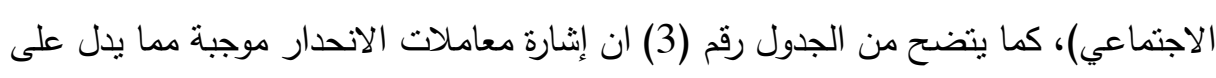

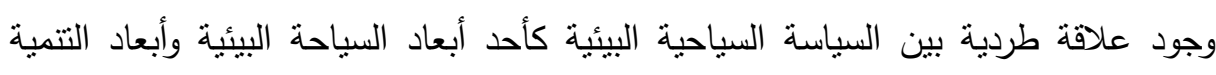

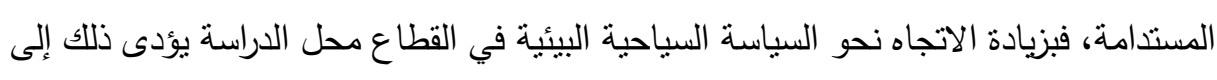
زيادة التتمية المستدامة لدي العاملين. مما سبق يتضح عدم صحة الفرض الرئيسي الأول وصحة الفرض البديل: " يوجد تأثيراً

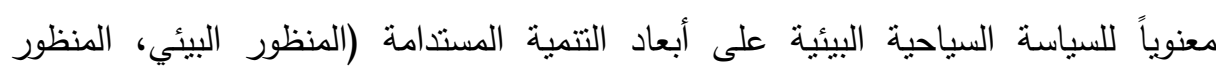
الاقتصادي والتقني، المنظور الاجتماعي) في القطاع محل الدراسة ". 
r ـ اختبار الفرض الرئيسي الثانى: " لا يوجد تأثيراً معنوياً للتخطيط الاقتصادي المستدام كأحد أبعاد السياحة البيئية على أبعاد التنمية المستدامة (المنظور البيئي، المنظور الاقتصادي ئتئي

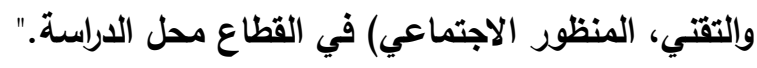

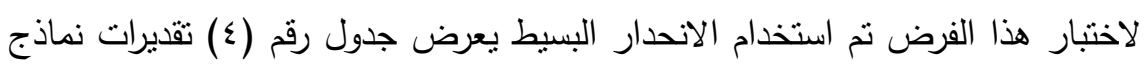
الانحدار البسيط لانحدار المتغيرات التابعة ( منوسط آراء العينة حول أبعاد التتمية المستدامة) على التخطيط الاقتصادي المستدام كأحد أبعاد السياحة البيئية.

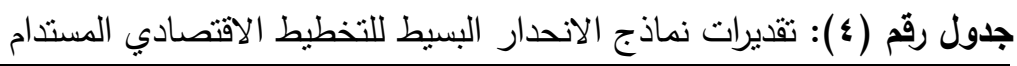

\begin{tabular}{|c|c|c|c|c|c|c|}
\hline \multicolumn{4}{|c|}{ التقديرات } & \multirow{2}{*}{$\begin{array}{c}\mathbf{F} \\
\text { (sig.) }\end{array}$} & \multirow{2}{*}{ التصديد } & \multirow{2}{*}{ المتغيرات التابعة } \\
\hline Sig. & $\mathbf{t}$ & प & & & & \\
\hline$\cdot, \cdots$ & $r, \cdot r_{1}$ & $\cdot, q \cdot V$ & الثابت & \multirow[b]{2}{*}{$|r r, r v|$} & \multirow[b]{2}{*}{ - 9 Y } & \multirow[b]{2}{*}{ المنظور البيئي } \\
\hline$\cdot, \cdots$ & $11,1 \cdot v$ & $1, r \leq 9$ & الاقتصناديط التخطيط & & & \\
\hline$\cdot, \ldots$ & rזו, & • IAY & الثابت & \multirow[b]{2}{*}{$\begin{array}{l}V, A Y \leq \\
\cdot, \cdot 19\end{array}$} & \multirow[b]{2}{*}{$\cdot, \mathrm{V} 00$} & \multirow[b]{2}{*}{ المنظور الاقتصادي } \\
\hline$\cdot, \cdots$ & Y, $\vee १ \vee$ & $\cdot, 971$ & الالقتصاديط & & & \\
\hline$\cdot, \ldots$ & $\cdot, 0 \mathrm{~V}$ & $\cdot, 710$ & الثابت & \multirow[b]{2}{*}{$\begin{array}{l}V, r q) \\
\cdot, \cdot r r\end{array}$} & \multirow[b]{2}{*}{$\cdot, \wedge 10$} & \multirow[b]{2}{*}{ المنظور الاجتماعي } \\
\hline$\cdot, \cdots$ & $r, v \backslash q$ & •, & الاقتصناديط التخطيط & & & \\
\hline
\end{tabular}

SPSS V25.المصدر: من إعداد الباحثين من واقع مخرجات برنامج

يتضح من الجدول رقم (4) معنوية نموذج انحدار المنظور البيئي على التخطيط

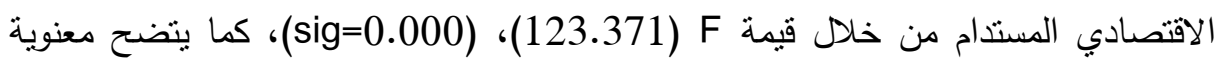
معامل الانحدار والحد الثابت عند مستوى معنوية 5\%. وبلغت قيمة معامل التحديد (0.925) مما يدل على أن المتغير المستقل (التخطيط الاقتصادي المستدام كأحد أبعاد السياحة البيئية) يفسر 92.5\% من التغيرات التى تحدث في المتغير التابع (متوسط آراء العينة حول المنظور 
معنوية نموذج انحدار المنظور الاقتصادي والتقني على التخطيط الاقتصادي المستدام

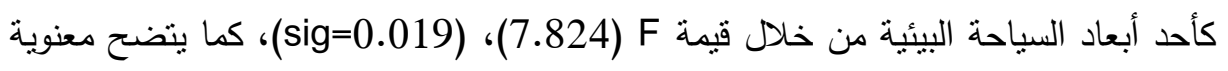
معامل الانحدار وعدم معنوية الحد الثابت عند مستوى معنوية 5\%. (0.755) مما يدل على أن المتغير المستقل (التخطيط الاقتصادي المستدام كأحد أبعاد السياحة البيئية) يفسر 75.5\% من التغيرات التى تحدث في المتغير التابع (منتسط آراء العينة حول المنظور الاقتصادي والثقني). معنوية نموذج انحدار المنظور الاجتماعي على التخطيط الاقتصادي المستدام كأحد أبعاد

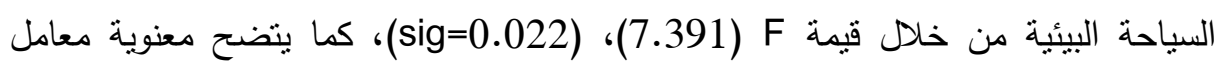

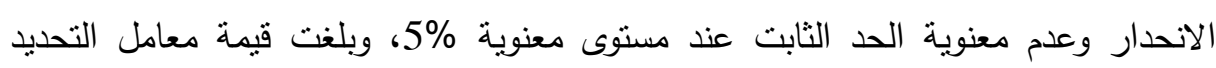
(0.815) مما يدل على أن المتغير المستقل (التخطيط الاقتصادي المستدام كأحد أبعاد السياحة البيئية) يفسر 81.5\% من التغيرات التى تحدث في المتغير التابع (متوسط آراء العينة حول المنظور الاجتماعي).

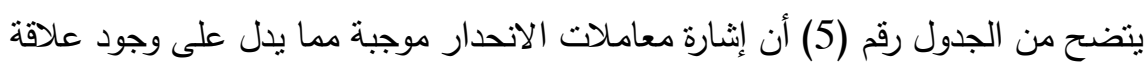

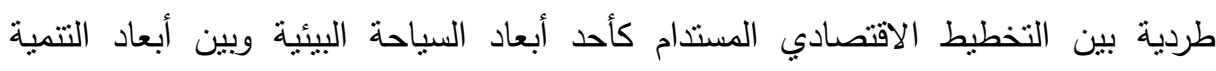

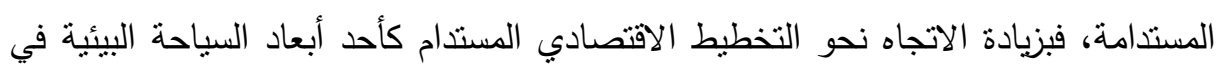
القطاع محل الدراسة يؤدى ذلك الى زيادة التتمية المستدامة. مما سبق يتضح عدم صحة الفرض الرئيسي الثاني وصحة الفرض البديل: " يوجد تأثيراً معنوياً للتخطيط الاقتصادي المستدام كأحد أبعاد السياحة البيئية على أبعاد التتمبية المستدامة لئية

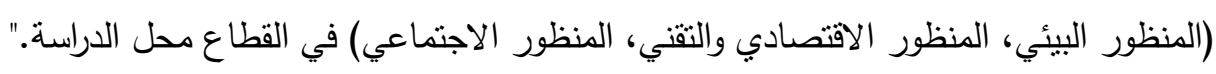

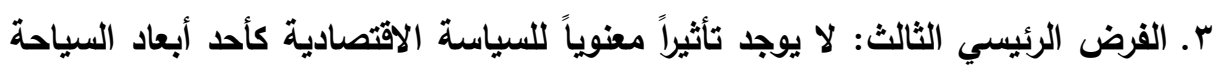

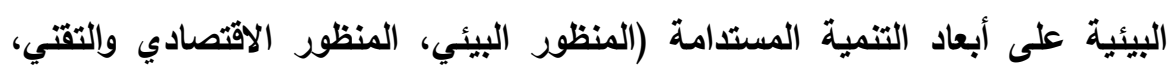

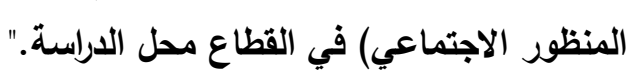

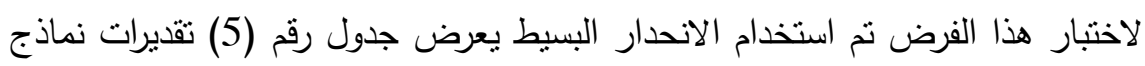
الانحدار البسيط لانحدار المتغيرات التابعة (متوسط آراء العينة حول أبعاد التتمية المستدامة) على السياسة الاقتصادية كأحد أبعاد السياحة البيئية. 
جدول رقم (ه): تقديرات نماذج الانحدار البسيط للسياسة الاقتصادية

\begin{tabular}{|c|c|c|c|c|c|c|}
\hline \multicolumn{4}{|c|}{ التقديرات } & \multirow{2}{*}{$\begin{array}{c}\mathbf{F} \\
(\mathbf{s i g} .)\end{array}$} & \multirow{2}{*}{$\begin{array}{l}\text { التحاميد } \\
\text { R }^{2}\end{array}$} & \multirow{2}{*}{ المتغيرات التابعة } \\
\hline Sig. & $\mathbf{t}$ & Q & & & & \\
\hline •,007 & $\cdot, 7,9$ & זTK, & الثابت & \multirow{2}{*}{$\begin{array}{c}T \Lambda, Y Y T \\
.\end{array}$} & \multirow[b]{2}{*}{$\cdot, \Lambda \vee Y$} & \multirow[b]{2}{*}{ المنظور البيئي } \\
\hline . & $\Lambda, Y_{T}$ & $1, .97$ & الاقتصيادية & & & \\
\hline$\cdot, 90 \mathrm{~V}$ &., .00 & $\cdot, .01$ & الثابت & \multirow{2}{*}{$\begin{array}{l}17,7 \cdot r \\
\cdot, ., r\end{array}$} & \multirow[b]{2}{*}{$\cdot, \vee \wedge \wedge$} & \multirow{2}{*}{ الاقتصادي والتقني } \\
\hline$\cdot, \cdot r$ & $r, \wedge \Lambda 1$ & $1, .17$ & الاقتصنادية & & & \\
\hline$\cdot, \leqslant Y$ & $\cdot, \wedge \leqslant Y$ & $\cdot, 9 \cdot 1$ & الثابت & \multirow{2}{*}{$\begin{array}{l}1,109 \\
., .1 V\end{array}$} & \multirow[b]{2}{*}{$\cdot, 919$} & \multirow{2}{*}{ الاجنماعي } \\
\hline$\cdot, .1 V$ & r,10T & $\cdot, \vee>70$ & الاقتصبادية & & & \\
\hline
\end{tabular}

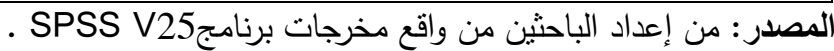

يتضح من الجدول رقم (6) معنوية نموذج انحدار المنظور البيئي على السياسة الاقتصادية من خلال قيمة F F (68.226)، (sig=0.000)، كما يتضح معنوية معامل الانحدار وعدم

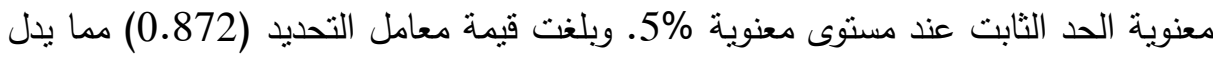
على أن المتغير المستقل (السياسة الاقتصادية كأحد أبعاد السياحة البيئية) يفسر الئه التغيرات النى تحدث في المتغير التابع (متوسط آراء العينة حول المنظور البيئي). معنوية نموذج انحدار المنظور الاقتصادي والتقني على السياسة الاقتصادية كأحد أبعاد

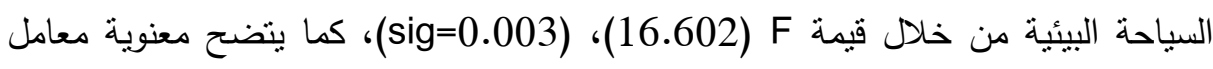
الانحدار وعدم معنوية الحد الثابت عند مسنوى معنوية 5\%. وبلغت فئه قيمة معامل التحديد (0.788) مما يدل على أن المتغير المستقل (السياسة الاقتصادية كأحد أبعاد السياحة البيئية) يفسر 78.8\% من التغيرات التى تحدث في المتغير التابع (متوسط آراء العينة حول المنظور الاقتصادي والتقني).

معنوية نموذج انحدار المنظور الاجتماعي على السياسة الاقتصادية كأحد أبعاد السياحة

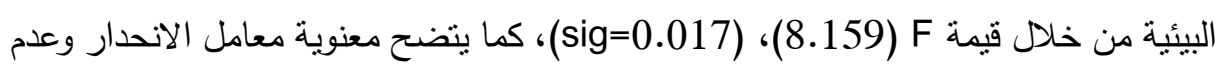
معنوية الحد الثابت عند مستوى معنوية 5\%. وبلغت قيمة معامل التحديد (0.919) مما يدل 
على أن المتغير المستقل (السياسة الاقتصادية كأحد أبعاد السياحة البيئية) يفسر 91.9\% من التغيرات التى تحدث في المتغير التابع (منوسط آراء العينة حول المنظور الاجتماعي).

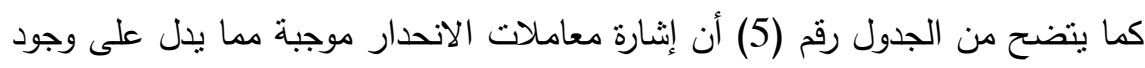

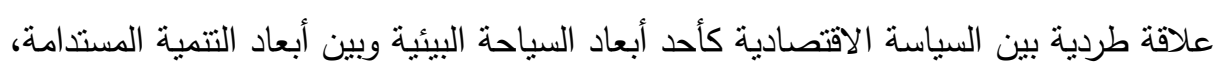

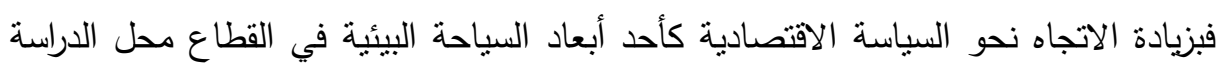
يؤدى ذلك إلى زيادة التتمية المستدامة.

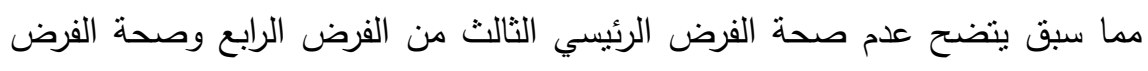

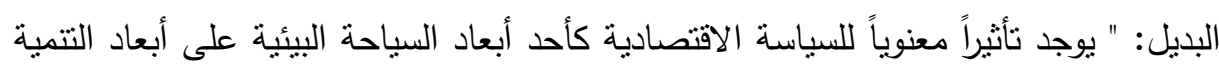

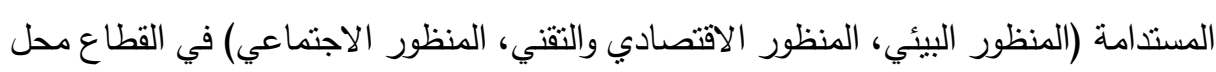

ـ. الفرض الرئيسي الرابع:" لا يوجد تأثيراً معنوياً للتشريعات السياحية البيئية كأحد أبعاد السياحة البيئية على أبعاد التنمية المستدامة (المنظور البيئي، المنظور الاقتصادي

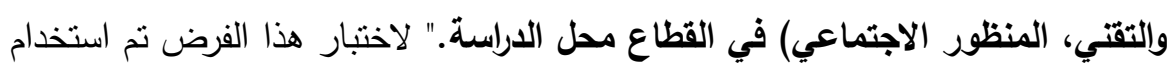

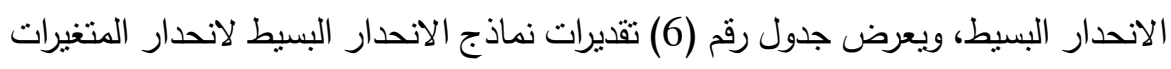
التابعة (متوسط آراء العينة حول أبعاد التتمية المستدامة) على التشريعات السياحية البيئية. جدول رقم (؟): نقديرات نماذج الانحدار البسيط للنتريعات السياحية البيئية

\begin{tabular}{|c|c|c|c|c|c|c|}
\hline \multicolumn{4}{|c|}{ التقديرات } & \multirow{2}{*}{$\begin{array}{c}\mathbf{F} \\
(\mathbf{s i g} .)\end{array}$} & \multirow{2}{*}{ 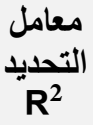 } & \multirow{2}{*}{ التابعة التغرات } \\
\hline Sig. & $\mathbf{t}$ & Q & & & & \\
\hline$\cdot, \ldots$ & $Y \Lambda, \varepsilon r$ & $0, \leqslant 0 \leqslant$ & الثابت & \multirow[b]{2}{*}{$\begin{array}{l}07,17 \\
., \ldots\end{array}$} & \multirow[b]{2}{*}{$\cdot, \wedge \leqslant 9$} & \multirow[b]{2}{*}{ البئزور } \\
\hline$\cdot, \cdots$ & $V, \varepsilon q \leq$ & $\cdot, 091$ & التشريعات السياحية & & & \\
\hline$\cdot, \ldots$ & $14, .19$ & $0, .17$ & الثابت & \multirow{2}{*}{$\begin{array}{l}7,971 \\
\cdot, \cdot Y_{0}\end{array}$} & \multirow[b]{2}{*}{$\cdot, V Y T$} & \multirow{2}{*}{ الاقتصنادي } \\
\hline$\cdot$, ro & r, & $\cdot, \leqslant 70$ & التشريعات البياحية & & & \\
\hline$\cdot, \ldots$ & $T \Gamma, 1 Y \varepsilon$ & $\varepsilon, \wedge \wedge \wedge$ & الثابت & \multirow{2}{*}{$\begin{array}{l}T, Y, r \\
\cdot, \cdot Y A\end{array}$} & \multirow[b]{2}{*}{$\cdot, \wedge \leq Y$} & \multirow[b]{2}{*}{ الاجنماعي } \\
\hline$\cdot, \cdot r \wedge$ & $r, 079$ & $\cdot, r q \wedge$ & التشريعات البيئية & & & \\
\hline
\end{tabular}

المصدر: من إعداد الباحثين من واقع مخرجات برنامج SPSS V25 
يتضح من الجدول رقم (6) معنوية نموذج انحدار المنظور البيئي على التشريعات السباحية

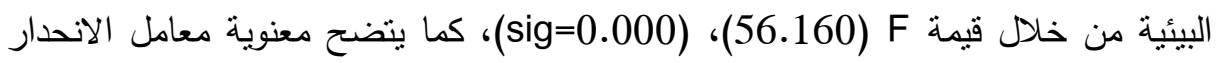

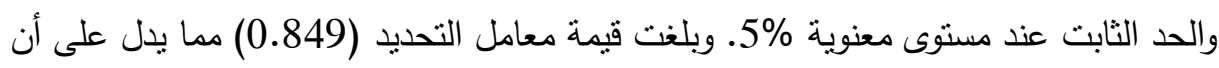

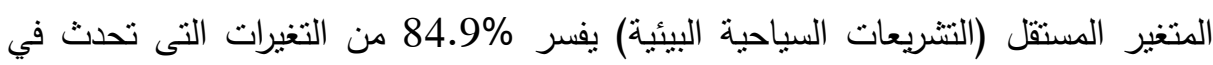
المتغير التابع (منوسط آراء العينة حول المنظور البيئي).

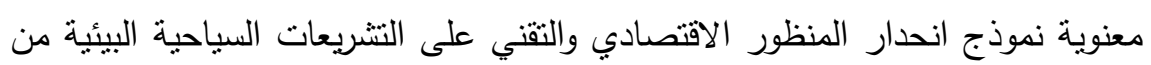
خلال قيمة F F (6.961)، (sig=0.025)، كما يتضح معنوية معامل الانحدار والحد الثابت عند مستوى معنوية 5\%. وبلغت قيمة معامل التحديد (0.723) مما يدل على أن المتغير

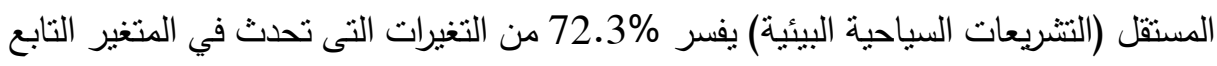
(متوسط آراء العينة حول المنظور الاقتصادي والتقني)، ومعنوية نموذج انحدار المنظور

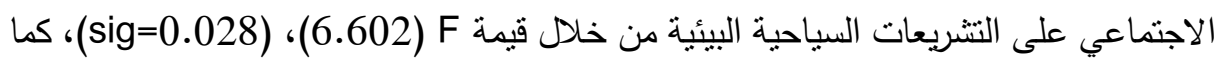
يتضح معنوية معامل الانحدار والحد الثابت عند مستوى معنوية 5\%، وبلغت لئت قيمة معامل التحديد (0.842) مما يدل على أن المتغير المستقل (التشريعات السياحية البيئية) يفسر 84.2\% من التغيرات التى تحدث في المتغير التابع (متوسط آراء العينة حول المنظور (الاجتماعي).

يتضح من الجدول رقم (6) أن إثارة معاملات الانحدار موجبة مما يدل على وجود علاقة

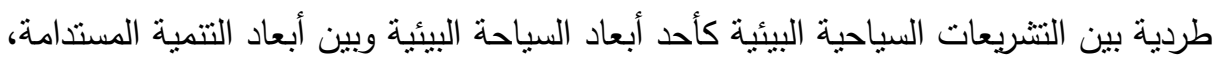

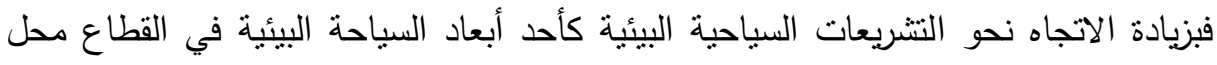

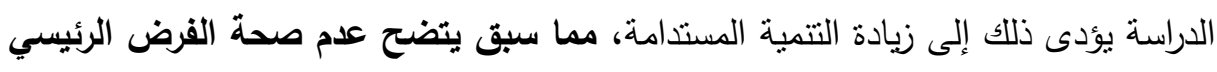

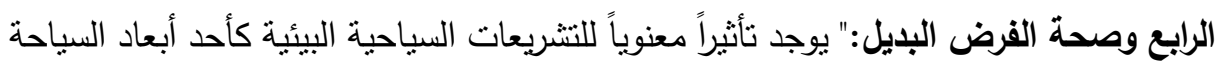

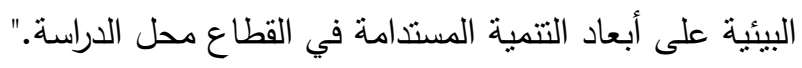


هـ الفرض الرئيسي الخامس: " لا يوجد تأثيراً معنوياً للحوافز المالية والضريبية الخضراء كأحد

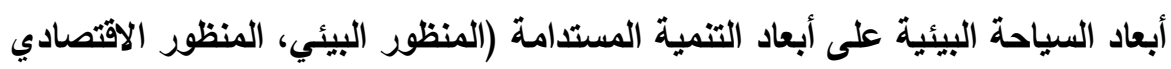

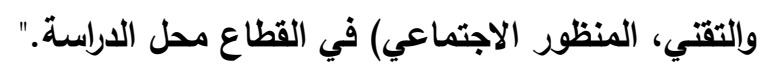
لاختبار هذا الفرض نم استخدام الانحدار البسيط يعرض جدول رقم الاجم (7) تقديرات نماذج الانحدار البسيط لانحدار المتغيرات التابعة (منوسط آراء العينة حول أبعاد التتمية المستدامة) على الحوافز المالية والضريبية الخضراء.

جدول رقم (V): تقديرات نماذج الانحدار البسيط للحوافز المالية والضريبية الخضراء

\begin{tabular}{|c|c|c|c|c|c|c|}
\hline \multicolumn{4}{|c|}{ التقديرات } & \multirow{2}{*}{$\begin{array}{c}\mathbf{F} \\
\text { (sig.) }\end{array}$} & \multirow{2}{*}{ 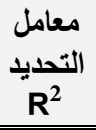 } & \multirow{2}{*}{ المتغيرات التابعة } \\
\hline Sig. & $\mathbf{t}$ & $\square$ & & & & \\
\hline$\cdot, \ldots$ & TV,OTr & וזד, 0, & الثابت & \multirow{2}{*}{$\begin{array}{l}r, 1 Y T \\
\cdot, \ldots\end{array}$} & \multirow[b]{2}{*}{$\cdot, \lambda T 1$} & \multirow{2}{*}{ المنظور البيئي } \\
\hline$\cdot, \ldots$ & $V, \Lambda \wedge r$ & 要, & والضريبية الخضراء الحالية & & & \\
\hline,,$\ldots$ & $11,01 Y$ & $0, Y \div \leqslant$ & الثابت & \multirow[b]{2}{*}{$\begin{array}{l}\vee, 99 \vee \\
\cdot, .11\end{array}$} & \multirow[b]{2}{*}{$\cdot, \vee \vee १ ৭$} & \multirow[b]{2}{*}{ المنظور الاقتصادي } \\
\hline$\cdot, \cdot 11$ & 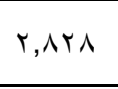 & $\cdot, 00$ & 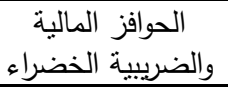 & & & \\
\hline$\cdot, \cdots$ & $11, \leqslant 79$ & $\varepsilon, 9 \% 0$ & الثابت & \multirow{2}{*}{$\begin{array}{l}0, \varepsilon 1 Y \\
\cdot, \cdot \leq r\end{array}$} & \multirow[b]{2}{*}{ • } & \multirow[b]{2}{*}{ المنظور الاجتماعي } \\
\hline$\cdot, \cdot \leq r$ & דוr, & - & 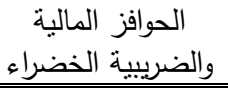 & & & \\
\hline
\end{tabular}

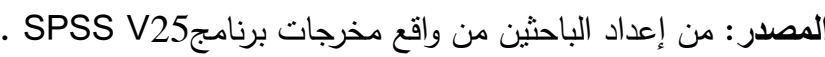

يتضح من الجدول رقم (7) معنوية نموذج انحدار المنظور البيئي على الحوافز المالية والضريبية الخضراء من خلال قيمة F (62.126)، (sig=0.000)، كما يتضح معنوية معامل

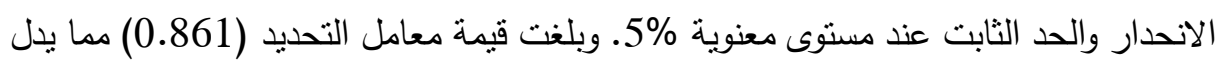

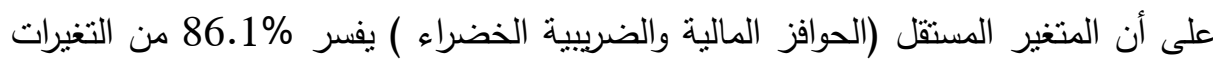
التى تحدث في المتغير التابع (منوسط آراء العينة حول المنظور البيئي).

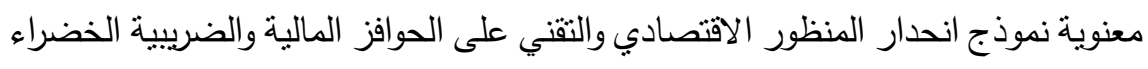
من خلال قيمة F F (7.997)، (sig=0.018)، كما يتضح معنوية معامل الاتحدار والحد الثابت عند مستوى معنوية 5\%. وبلغت قيمة معامل التحديد (799)، (0.79) مما يدل على أنى أن المتغير 
المستقل (الحوافز المالية والضريبية الخضراء) يفسر 79.9 من التغيرات التى تحدث في المتغير التابع ( منوسط آراء العينة حول المنظور الاقتصادي والتقني).

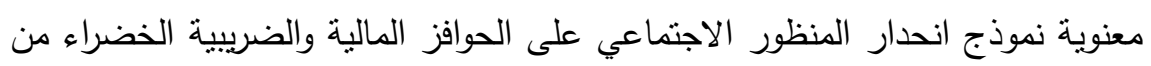
خلال قيمة F (5.412)، (sig=0.042)، كما يتضح معنوية معامل الانحدار والحد الثابت عند مستوى معنوية 5\%، وبلغت قيمة معامل التحديد (0.913) مما يدل على أن المتغير

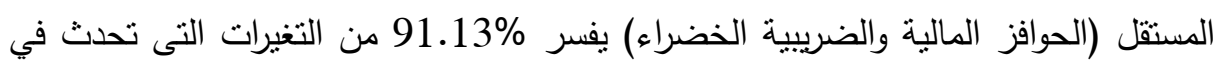
المتغير التابع (متوسط آراء العينة حول المنظور الاجتماعي).

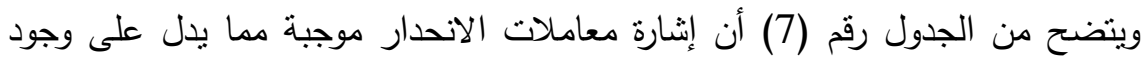
علاقة طردية بين الحوافز المالية والضريبية الخضراء كأحد أبعاد السياحة البيئية وبين أبعاد التتمية المستدامة، فبزيادة الاتجاه نحو الحوافز المالية والضريبية الخضراء كأحد أبعاد السياحة ولئه البيئية في القطاع محل الدراسة يؤدى ذلك إلى زيادة التتمية المستدامة. مما سبق يتضح عدم صحة الفرض الرئيسي الخامس وصحة الفرض البديل: " يوجد تأثيراً معنوياً للحوافز المالية والضريبية الخضراء كأحد أبعاد السياحة البيئية على أبعاد التتمية المستدامة (المنظور البيئي، المنظور الاقتصادي والتقني، المنظور الاجتماعي) في القطاع محل

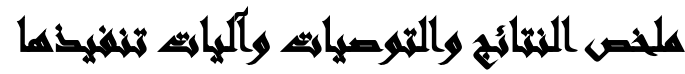

قام الباحثون بتخصيص هذا الجزء لعرض ملخص النتائج وكنلك التوصيات وآليات تنفيذها،

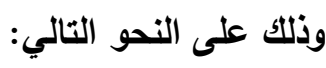
أ. أن أنتائج:

ا ـ وجود ارتباط طردي قوى بين (التخطيط الاقتصادي المستدام)، (السياسة السياحية البيئية)،

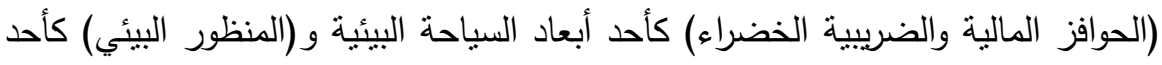
أبعاد التتمية المستدامة على التزتيب ومعنوي عند مستوى معنوية 1\% 
r. يوجد تأثيراً معنوياً لأبعاد السياحة البيئية (السياسة السياحية البيئية، التخطيط الاقتصادي

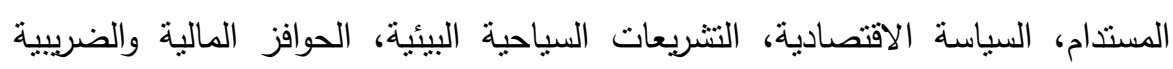

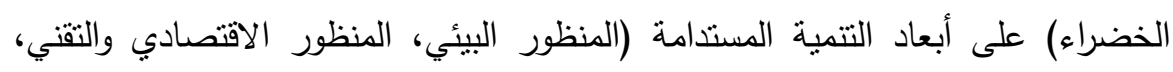
المنظور الاجتماعي) في القطاع محل الدراسة. r. تبني القطاع للسياحة البيئية يرفع من التنمية المستدامة بهاء ع. السياحة البيئية يزيد من المنظور البيئي لاي العاملين.

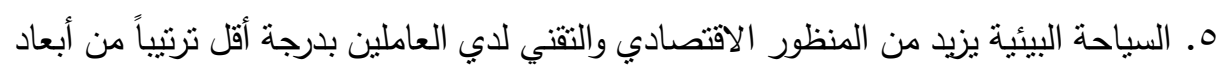
التتمية المستدامة. 7. يزيد المنظور الاجتماعي لدي العاملين نتيجة السياحة البيئية بدرجة هي الأقل ترتيباً على اللى الإطلاق من باقي أبعاد التتمية المستدامة. ب. التوصيات وآليات تنفيذها: في ضوء ما أسفرت عنه نتائج الدراسة يطيب للباحثين أن يختتموا

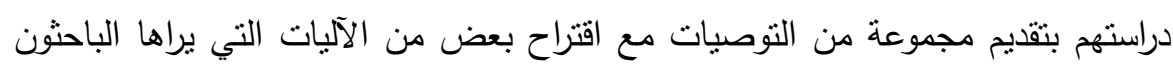

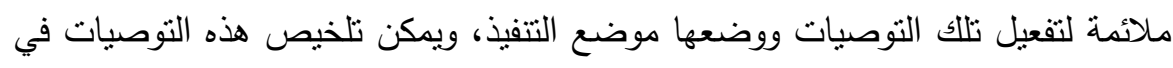
البنود التالية، والجدول رقم (8) التالي يوضح توصيات الدراسة وخطوات النطبيق وجهة

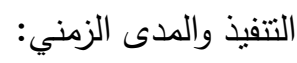


جدول رقم (^): يوضح توصيات الدراسة وخطوات التطبيق وجهة التنفيذ

\begin{tabular}{|c|c|c|c|c|}
\hline الزمنيى & جهة التنفيذ & خطوات التطبيق & التوصية & p \\
\hline بصنمرة & 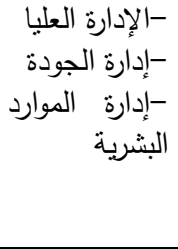 & 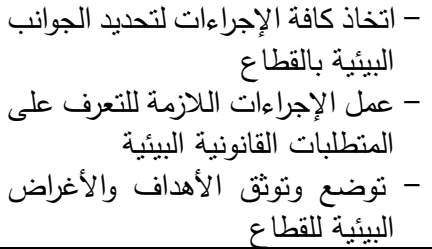 & 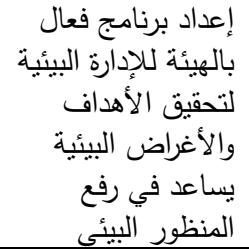 & 1 \\
\hline بصنمرة & 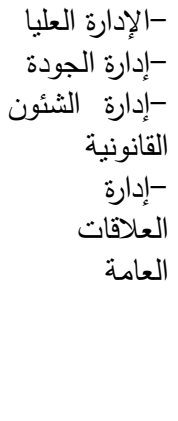 & 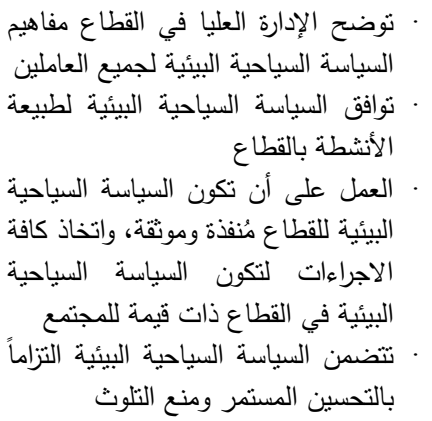 & 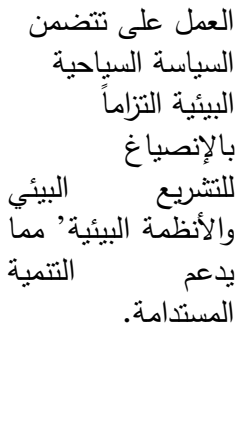 & $r$ \\
\hline بصتمرة & 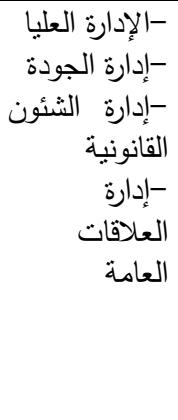 & 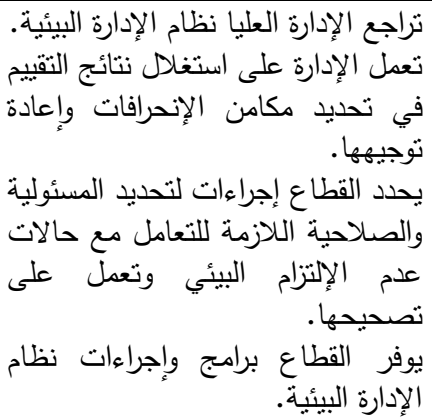 & 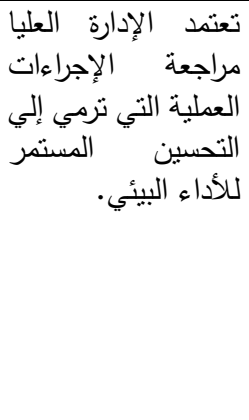 & r \\
\hline
\end{tabular}

المصدر: من إعداد الباحثين

\section{2all}

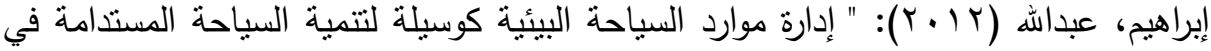

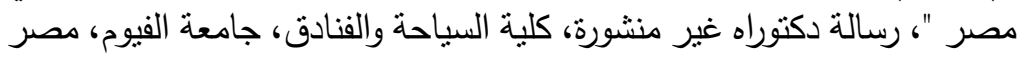

البلتاجي، ممدوح (999 (19): "السياحة البيئية في مصر ، مجلة البحوث السياحية، الطبعة الأولي، القاهرة 


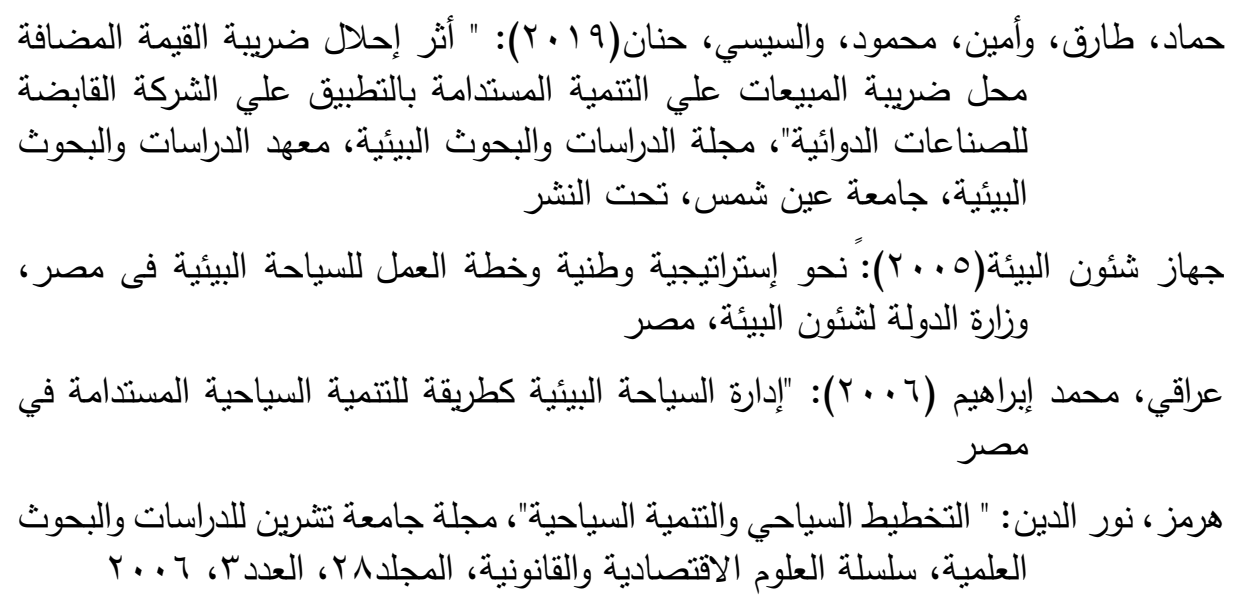

Benavides, D. D., \& Perez - Ducy, E, (2001, May). Tourism in the least developed countries. World Tourism Organization, United Nations Conference on Trade and Development, Brussels

Bonn, M. A., Joseph, S. \&Dai, and M. (2005) an empirical analysis of eco generalists visiting Florida: 1998-2003.

Chunai, X., \& Qin, L. (2018, September). The Sustainable Development of Symbol Consumption and Cultural Ecotourism. In Fifth International Conference on Public Management: International Collaboration for Innovated Public Governance (ICPM 2018). Atlantis Press.

Coronado Martínez, Y., Rosas Baños, M., \& Cerón Monroy, H. (2018). Ecotourism as a path to sustainable development in an isolated Magic Town: The case study of La Trampa, Mexico. Journal of Tourism Analysis: Revista de Análisis Turístico, 25(1), 23-38.

European Commission, (1995), Green Paper on tourism DGXXIII, Brussels. 
Filho, A.p (1998). Environmental / Culture / tourism: Recommendations for a harmonic relationship. In International Scientific Conference on Tourism in the $21^{\text {st }}$ "Century, Tourism Development \& Environmental Control," Egypt.

Gunn, C.A. (1994) Tourism planning, basics, concepts, cases Washington, DC: Taylor \& Francis.

Horochowski, K., \& Moisey, R. N. (2001). Sustainable tourism: the effect of local participation in Honduran ecotourism development. Tourism, recreation and sustainability: Linking culture and the environment, 163-175.

http://www.tda.gov.eg

Liu, C. R., Lin, W. R., Wang, Y. C., \& Chen, S. P. (2019). Sustainability indicators for festival tourism: A multi-stakeholder perspective. Journal of Quality Assurance in Hospitality \& Tourism, 20(3), 296-316.

Moisey, R.N., \& McCool, S.F (2001). Sustainable tourism in the $21^{\text {st }}$ century: lessons from the past; challenges, UK.CABI Publishing.

Mowforth, M., \& Munt, I. (1998) Tourism and sustainability: new tourism in the third world. London: Rutledge.

Phillips, A. (2000). Financing protected area managers (series No, 5). World Commission on protected areas.

Sambou, O., Riniwati, H., \& Fanani, Z. (2019). Socio-economic and Environmental Sustainability of Ecotourism: A Study in Ubud Monkey Forest-Bali, Indonesia. Journal of Indonesian Tourism and Development Studies, 7(3).

Sharply, R. (2001). The consumer behavior context of eco labelling. In X Font\& R.C. Buckley (Eds.), Tourism eco labelling: Certification and Promotion of sustainable management. UK: CABI Publishing.

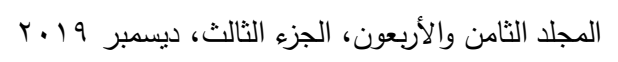


Timothy, D.J (2000). Cross- border partnership in tourism resource management: international parks along the US-Canada border. In B. Bramwell \& B. Lane (Eds.), Tourism collaboration and partnership, politics. Practice and sustainability (pp 20-43). Clevedon, UK: Channel View Publications.

UN ESCAP. (2001) Promotion of investment in tourism infrastructure. New York: Economic and social commission for Asia and the pacific.

Wahab (2001). Middle East. In A. Lockwood \&S. Medlike (Eds), Tourism and hospitality in the $21^{\text {st }}$ century. Oxford, UK: Butterworth - Heinemann.

Yunis, E. (2002), the framework of the international year of ecotourism and conditions for the sustainable development and management of ecotourism, sustainable development of ecotourism, web-Conference, Madrid, April 1-26. 
مجلة العلوم البيئية

معهد الدراسات والبحوث البيئية - جامعة عين شمس به

\title{
THE ECONOMIC AND ENVIRONMENTAL IMPACT OF ECO-TOURISM ON SUSTAINABLE DEVELOPMENT IN EGYPT
}

\author{
Samia Ibrahim(1); Safwat Abdel Salam $^{(2)}$; \\ Hoda Sayed $^{(3)}$ and Mahmoud Hamed ${ }^{(4)}$
}

1) Post Gard. Institute of Environmental Studies and Research, Ain Shams University 2) Faculty of Law, Ain Shams University.3) Faculty of Tourism and Hotels, Fayoum University.4) Faculty of Commerce, Ain Shams University

\begin{abstract}
This research aims at studying the economic and environmental impact of eco-tourism on sustainable development in Egypt. Research?? in the lack of application of the dimensions of sustainable development in the sector under study, which may be due to the lack of awareness and application of the concepts of the dimensions of eco-tourism in terms of economic and environmental sector, researchers in this study relied on a combination of inductive approach $U$ using a theoretical and field study method, the researchers used a survey list that was prepared for the purpose of collecting data according to the study variables. The researchers They also used the Alpha Kronbach coefficient to calculate the coefficient of stability. Using the study sample of 311 individuals,. The finding reveal the researchers have reached several results were the presence of a statistically significant impact between all dimensions of ecotourism and all dimensions of sustainable development, as well as the importance of the adoption of ecotourism to support Sustainable development in the General Authority for Tourism Development. the researchers recommended a number of recommendations, The most important recommendations of which are: Environmental tourism policy must include a commitment to formulate environmental legislation and

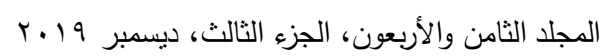


regulations, which supports sustainable development, and the preparation of an effective program for the environmental and economic management of ecotourism to support sustainable development.

Key Word: eco-tourism, sustainable development, General Authority for Tourism Development, Egypt. 